OPEN ACCESS

Edited by:

Zuben E. Sauna,

United States Food and Drug

Administration, United States

Reviewed by:

Rong Hai,

University of California, Riverside,

United States

Amit Golding,

United States Food and Drug

Administration, United States

${ }^{*}$ Correspondence:

Yariv Wine

yariwine@tauex.tau.ac.il

tThese authors have contributed equally to this work

Specialty section:

This article was submitted to Vaccines and Molecular Therapeutics,

a section of the journal

Frontiers in Immunology

Received: 16 September 2019 Accepted: 28 November 2019 Published: 18 December 2019

Citation:

Vaisman-Mentesh A, Rosenstein $S$ Yavzori M, Dror Y, Fudim E, Ungar $B$, Kopylov U, Picard O, Kigel A,

Ben-Horin S, Benhar I and Wine Y (2019) Molecular Landscape of Anti-Drug Antibodies Reveals the Mechanism of the Immune Response Following Treatment With TNFo Antagonists.

Front. Immunol. 10:2921 doi: 10.3389/fimmu.2019.0292

\section{Molecular Landscape of Anti-Drug Antibodies Reveals the Mechanism of the Immune Response Following Treatment With TNF $\alpha$ Antagonists}

\author{
Anna Vaisman-Mentesh ${ }^{1 \dagger}$, Shai Rosenstein ${ }^{1 \dagger}$, Miri Yavzori ${ }^{2}$, Yael Dror ${ }^{1}$, Ella Fudim ${ }^{2}$, \\ Bella Ungar ${ }^{2}$, Uri Kopylov ${ }^{2}$, Orit Picard ${ }^{2}$, Aya Kigel ${ }^{1}$, Shomron Ben-Horin ${ }^{2}$, Itai Benhar ${ }^{1}$ \\ and Yariv Wine ${ }^{1 *}$
}

${ }^{1}$ George S. Wise Faculty of Life Sciences, School of Molecular Cell Biology and Biotechnology, Tel Aviv University, Tel Aviv-Yafo, Israel, ${ }^{2}$ Gastroenterology Department, Sheba Medical Center and Sackler School of Medicine, Tel-Aviv University, Tel Aviv-Yafo, Israel

Drugs formulated from monoclonal antibodies (mAbs) are clinically effective in various diseases. Repeated administration of mAbs, however, elicits an immune response in the form of anti-drug-antibodies (ADA), thereby reducing the drug's efficacy. Notwithstanding their importance, the molecular landscape of ADA and the mechanisms involved in their formation are not fully understood. Using a newly developed quantitative bio-immunoassay, we found that ADA concentrations specific to TNF $\alpha$ antagonists can exceed extreme concentrations of $1 \mathrm{mg} / \mathrm{ml}$ with a wide range of neutralization capacity. Our data further suggest a preferential use of the $\lambda$ light chain in a subset of neutralizing ADA. Moreover, we show that administration of TNF $\alpha$ antagonists result in a vaccine-like response whereby ADA formation is governed by the extrafollicular $\mathrm{T}$ cell-independent immune response. Our bio-immunoassay coupled with insights on the nature of the immune response can be leveraged to improve mAb immunogenicity assessment and facilitate improvement in therapeutic intervention strategies.

Keywords: immunogenicity, anti-drug antibodies, next generation sequencing, antibody repertoire, proteomics, high-throughput sequencing, monoclonal antibody, biologics

\section{INTRODUCTION}

More than 30 years since the approval of the first therapeutic monoclonal antibody (mAb) for clinical use, the therapeutic $\mathrm{mAb}$ market has expanded exponentially, establishing $\mathrm{mAbs}$ as one of the leading biopharmaceutical therapeutic modalities (1). Although mAbs hold significant promise for improving human health, their repeated administration is often highly immunogenic and can elicit an undesirable anti-drug antibody (ADA) response (2). The formation of an ADA response interferes with the effect of the drug or neutralizes it thereby altering the drug's pharmacokinetic (PK) and pharmacodynamic (PD) properties and reducing its efficacy (3), and eventually may lead to a severe adverse immune reaction in humans (4).

Immunogenicity of $\mathrm{mAbs}$ and the formation of an $\mathrm{ADA}$ response has been suggested to be dependent on the interplay between factors related to the drug itself (e.g., non-human sequence, glycosylation, impurities, aggregation), to the patient (e.g., disease type, genetic factors, 
concomitant immunomodulators), or to the drug's route and frequency of administration $(5,6)$. However, the molecular mechanisms that lead to the induction of ADA are not wellunderstood and were initially thought to be related to the murine origin of the mAbs because they were recognized as "non-self" by the human immune system. This idea propelled the mAb discovery field to focus on engineering refined mAbs by reducing the non-human portions and developing chimeric, humanized, and fully human mAbs by using human libraries or humanized mice at the mAb discovery phase (7).

Unfortunately, this strategy did not abolish the immunogenicity potential of $\mathrm{mAbs}$ and the associated induction of ADA. The question of why and how ADA develop is further complicated by data indicating that some patients develop $\mathrm{ADA}$, and some do not, and by the observation that the extent of immunogenicity may differ among patients receiving the same $\mathrm{mAb}$ (8). ADA that develop in patients treated with an $\mathrm{mAb}$ can be stratified into two main categories: (1) neutralizing ADA (ntADA) that directly block and interfere with the drug's ability to bind its target, and (2) non-neutralizing ADA (i.e., binding $\mathrm{ADA}$ bADA) that recognize other epitopes on the drug while still retaining the $\mathrm{mAb}$ binding activity (9). nt ADA are generally considered to be more important in the clinical setting than $b$ ADA because they directly reduce a drug's efficacy. However, $b \mathrm{ADA}$ may indirectly reduce the therapeutic efficacy of an $\mathrm{mAb}$ by compromising bioavailability or accelerating drug clearance from the circulation. In both cases, ntADA and bADA substantially alter the $\mathrm{PK}$ and $\mathrm{PD}$ of the $\mathrm{mAb}$ being administered (10).

Originator and biosimilar tumor necrosis factor alpha (TNF $\alpha)$ antagonistic mAbs are used extensively in clinical settings to treat inflammatory bowel disease (IBD; e.g., Crohn's disease and ulcerative colitis), rheumatoid arthritis, and other chronic inflammatory associated disorders such as psoriasis, psoriatic arthritis, and ankylosing spondylitis (11). TNF $\alpha$ antagonists help reduce inflammatory responses by targeting both membranebound and soluble TNF $\alpha$. Neutralizing soluble TNF $\alpha$ prevents its binding to its receptor and impedes the secretion and upregulation of the signal cascade, thereby inhibiting its biological activity. The binding of $\mathrm{TNF} \alpha$ antagonists to transmembrane TNF $\alpha$ on immune effector cells causes their destruction by inducing cell apoptosis or cell lysis through reverse signaling (12).

Currently, five TNF $\alpha$ antagonists have been approved by both the U.S. Food and Drug Administration and the European Medicines Agency: infliximab (IFX), adalimumab (ADL), etanercept, golimumab, and certolizumab pegol (2). Additionally, several biosimilars have already been approved or are in various stages of development (13). Both IFX and ADL belong to the group of $\mathrm{TNF} \alpha$ antagonists and are routinely used in clinical settings to treat inflammatory diseases. IFX is a chimeric $\mathrm{mAb}$ (75\% human and $25 \%$ murine), whereas ADL is fully human. The reported immunogenicity extent of these drugs is inconsistent. Whereas, pharmaceutical companies report 1015 and $2.6-26 \%$ immunogenicity for IFX and ADL, respectively (14), clinical data suggest higher immunogenicity rates for these drugs (15). Patients treated with IFX and ADL can be stratified based on the characteristics of their response to treatment or lack thereof. Primary non-responders are patients whose disease does not respond to the drug at all, and a certain subset of these may be mediated via early formation of ADA $(15,16)$. Secondary nonresponders are patients who initially respond to the drug but later fail treatment, often due to development of ADA (for IFX, this was reported to develop mostly within 12 months of treatment initiation) (16).

Studies reporting immunogenicity following $\mathrm{mAb}$ administration and $\mathrm{ADA}$ prevalence have been inconsistent due in part to the various assay formats used to monitor immunogenicity in the clinic (17). Current limitations of each available format might reduce utility in clinical and research settings and complicate data interpretation. Some assays have a poor dynamic range and may generate false negative results because of interfering interaction with another circulating drug, or conversely, false positive results due to the presence of other antibodies such as rheumatoid factor (18). The pros and cons of available ADA detection assays were previously elaborated, and the formation of ADA following treatment with IFX, ADL, and other $\mathrm{TNF} \alpha$ antagonists, including newly developed biosimilars, have been extensively studied and reviewed elsewhere (5, 19-21).

Notwithstanding the effort invested in understanding the reasons that $\mathrm{mAb}$ immunogenicity and strategies to increase $\mathrm{mAb}$ efficacy, little is known about the molecular mechanism that governs the formation of ADA following treatment with an $\mathrm{mAb}$.

In this study, we investigated the molecular landscape of ADA following treatment with $\mathrm{TNF} \alpha$ antagonists. First, we developed a simple bio-immunoassay that accurately quantifies ADA levels in patient sera. We further modified the bioimmunoassay to evaluate the neutralization capacity of the ADA. Next, we aimed to profile the immune response following $\mathrm{mAb}$ administration. We used flow cytometry to determine the frequency of $\mathrm{B}$ cells in the circulation and whether the dynamics of the immune response was akin to vaccine response. Finally, we used next-generation sequencing (NGS) and highresolution shotgun tandem mass spectrometry (LC-MS/MS) to elucidate the molecular composition of serum ADA. Using our bio-immunoassay we found that ADA levels in sera from 54 patients ranged between 2.7 and $1268.5 \mu \mathrm{g} / \mathrm{ml}$. The modified bio-immunoassay enabled us to differentiate between patients who have high and low neutralization capacity. Interestingly, we found that patients with a high neutralization capacity showed a strong bias in the $\lambda / \kappa$ light chain ratio thereby suggesting that $n t$ ADA exhibits a preference for $\lambda$ light chains.

To elucidate the nature of the immune response following drug administration we chose to study a patient with IBD who was treated with IFX and who had high ADA levels and neutralization capacity. At 10 days (D10) following IFX infusion, the patient exhibited an $\sim 13$-fold increase in the frequency of plasmablasts $(\mathrm{PB})$ and unchanged frequency of activated memory B cells ( $\mathrm{mBC}$ ), compared with the pre-infusion time point (D0). Comparative NGS analysis of the antibody heavy chain variable region $\left(\mathrm{V}_{\mathrm{H}}\right)$ from isolated $\mathrm{PB}$ at $\mathrm{D} 0$ and $\mathrm{D} 10$, showed a significant temporal decrease in the level of somatic hypermutation (SHM) and an increase in the length of the complementary determining region 3 of the antibody heavy chain (CDRH3). 
Moreover, the proteomic analysis of serum ADA supports the observation obtained from the neutralization capacity assays, that a preference for using $\lambda$ light chains exists. These data suggest a possible mechanism whereby the humoral immune response following the administration $\mathrm{TNF} \alpha$ antagonists is governed by a $\mathrm{T}$ cell-independent (TI) response. This response may be induced by the formation of immunocomplexes (drug-TNF $\alpha$ ADA) serving as a strong driver of immunogenicity that in-turn diverts the immune response to TI pathway were $\mathrm{B}$ cells are activated by $\mathrm{B}$ cell receptor (BCR) cross-linking.

\section{MATERIALS AND METHODS}

\section{Over Expression and Purification of rhTNF $\alpha$}

The sequence-encoding residues Val77-Leu233 of human TNF $\alpha$ was cloned and fused to the N-terminal 6xHis tag in pET-28a+ vector (Novagen) and transformed into Escherichia coli Rosetta (DE3) cells (Novagen). A single colony was inoculated into $2 \mathrm{ml} \mathrm{LB}$ supplemented with Kanamycin at final concentration of $100 \mu \mathrm{g} / \mathrm{ml}$ and incubated overnight (O.N.) at $37^{\circ} \mathrm{C}, 250 \mathrm{RPM}$. The culture was next re-inoculated into a $0.5 \mathrm{~L}$ Erlenmeyer containing LB supplemented with Kanamycin, and grown at $37^{\circ} \mathrm{C} 250$ RPM until O.D. $600 \sim 0.6-0.8$ was reached. Induction was carried out by supplementing bacterial culture with IPTG ( $0.1 \mathrm{mM}$ final concentration) and incubating the culture for $3 \mathrm{~h}$ at $37^{\circ} \mathrm{C}, 250 \mathrm{RPM}$. Bacterial cells were harvested by centrifugation at 8,000 RPM, $15 \mathrm{~min}$, at $10^{\circ} \mathrm{C}$ (SORVALL RC6 Plus, Thermo Fisher Scientific) and cell pellet was stored O.N. at $-20^{\circ} \mathrm{C}$. Next, pellet was re-suspended in $30 \mathrm{ml}$ of binding buffer ( $50 \mathrm{mM}$ sodium phosphate buffer $\mathrm{pH} 8.0,300 \mathrm{mM} \mathrm{NaCl}$, $10 \mathrm{mM}$ imidazole) and sonicated on ice for 8 cycles of $30 \mathrm{~s}$ pulse with 2 min pause (W-385 sonicator, Heat Systems Ultrasonics). Following sonication, cells were centrifuged at 12,000 RPM, $30 \mathrm{~min}, 4^{\circ} \mathrm{C}$ (SORVALL RC 6+) and supernatant was applied to a HisTrap affinity column (GE Healthcare) that was preequilibrated with binding buffer. All affinity purification steps were carried out by connecting the affinity column to a peristaltic pump with flow rate of $1 / \mathrm{ml} / \mathrm{min}$. Column was washed with 5 column volumes (CV) of wash buffer ( $50 \mathrm{mM}$ Sodium phosphate, pH 8.0, $300 \mathrm{mM} \mathrm{NaCl}, 10 \%$ glycerol, $20 \mathrm{mM}$ imidazole) followed by elution of rhTNF $\alpha$ with $5 \mathrm{CV}$ of elution buffer $(50 \mathrm{mM}$ Sodium phosphate, $\mathrm{pH}$ 6.0, $300 \mathrm{mM} \mathrm{NaCl}, 10 \%$ glycerol, $500 \mathrm{mM}$ imidazole). Elution was collected in $1 \mathrm{ml}$ fractions and were analyzed by $12 \%$ SDS-PAGE. Fractions containing clean rhTNF $\alpha$ were merged and dialyzed using Amicon Ultra (Mercury) cutoff $3 \mathrm{~K}$ against PBS ( $\mathrm{pH} 7.4$ ). Dialysis products were analyzed by $12 \%$ SDS-PAGE for purity and concentration was measured using Take-5 (BioTek Instruments). To test functionality of the produced rhTNF $\alpha, 96$ well-plate (Nunc MaxiSorp ${ }^{\text {TM }}$ flat-bottom, Thermo Fisher Scientific) was coated with $1 \mu \mathrm{g} / \mathrm{ml}$ (in PBS) of purified $\operatorname{rhTNF} \alpha$ and commercial hTNF $\alpha$ (PHC3011, Thermo Fisher Scientific) and incubated at $4^{\circ} \mathrm{C}$ O.N. ELISA plates were then washed three times with PBST $(0.1 \%$ v/v Tween 20 in PBS) and blocked with $300 \mu \mathrm{l}$ of $2 \% \mathrm{w} / \mathrm{v}$ BSA in PBS for $1 \mathrm{~h}$ at $37^{\circ} \mathrm{C}$. Next, ELISA plates were washed three time with PBST, and incubated for $1 \mathrm{~h}$, room temperature (RT) in triplicates with anti-TNF $\alpha \mathrm{mAb}$ (Infliximab or Adalimumab) in $2 \% \mathrm{w} / \mathrm{v} \mathrm{BSA}$,
PBS at the starting concentration of $50 \mathrm{nM}$ with 3-fold dilution series. Plates were then washed three times with PBST with $30 \mathrm{~s}$ incubation time at each washing cycle. For detection, 50 $\mu \mathrm{l}$ of anti-human H+L HRP conjugated antibody (Jackson) was added to each well $(1: 5,000$ ratio in $2 \% \mathrm{w} / \mathrm{v}$ BSA in PBS) and incubated for $1 \mathrm{~h}$ at RT, followed by three washing cycles with PBST. Developing was carried out by adding $50 \mu \mathrm{l}$ of $3,3^{\prime}, 5,5^{\prime}$ Tetramethylbenzidine (TMB, Southern Biotech) and reaction was quenched by adding $50 \mu \mathrm{l} 0.1 \mathrm{M}$ sulfuric acid. Plates were read using the Epoch Microplate Spectrophotometer ELISA plate reader (BioTek Instruments).

\section{Over Expression and Purification of IdeS}

The coding sequence corresponding to amino acid residues 38339 of $S$. pyogenes IdeS (numbered from the start of the signal sequence) was sub-cloned into the expression vector pET28b (Novagen). The coding sequencing was sub-cloned at the $3^{\prime}$ end of Thioredoxin 6xHis-TEV. The complete construct was subcloned as previously described (22) and was kindly donated by Dr. Ulrich von Pawel-Rammingen from the Department of Molecular Biology, Umea University. The transformation of pET-TRX_b plasmid harboring the IdeS encoding gene (pETIdeS) was carried out as follows: $200 \mu \mathrm{l}$ of chemical-competent E. coli BL21-DE3 cells were thawed on ice for $20 \mathrm{~min}$. Fifty nanograms of the plasmid pET-IdeS was added to the thawed competent cells and incubated on ice for $20 \mathrm{~min}$ with gentle mixing every $5 \mathrm{~min}$. Next, heat shock was applied by incubating the cells at $42^{\circ} \mathrm{C}$ for $2 \mathrm{~min}$ followed by incubation on ice water for $2 \mathrm{~min}$. For phenotypic expression, $800 \mu \mathrm{l}$ of $\mathrm{LB}$ was added, and cells were incubated at $37^{\circ} \mathrm{C}, 250 \mathrm{RPM}$ for $1 \mathrm{~h}$ in a horizontal position. Cells were plated on LB agar supplemented with Kanamycin and incubated at $37^{\circ} \mathrm{C}$ overnight (O.N). Single colony was inoculated into $2 \mathrm{ml} \mathrm{LB}$ supplemented with Kanamycin and incubated O.N. at $37^{\circ} \mathrm{C}, 250$ RPM. Next day, $2 \mathrm{ml}$ from the grown cultures were inoculated into two $2 \mathrm{~L}$ flasks, each containing each $500 \mathrm{ml} \mathrm{LB}$ supplemented with Kanamycin. Over expression and purification of IdeS was carried out as described for $\operatorname{rhTNF} \alpha$ with a minor modification as follow: Ides was eluted with imidazole gradient $(50,150,500 \mathrm{mM}$ imidazole), total of $20 \mathrm{ml}$. Twenty fractions of $1 \mathrm{ml}$ were collected from each elution step and evaluated for their purity using $12 \%$ SDS-PAGE. All fractions containing clean IdeS were merged and dialyzed O.N. at $4^{\circ} \mathrm{C}$ against $4 \mathrm{~L}$ of PBS (pH 7.4), using SnakeSkin dialysis tubing with $10 \mathrm{kDa}$ cutoff (Thermo Fisher Scientific). Dialysis products were analyzed by $12 \%$ SDS-PAGE.

\section{Production of $\mathrm{mAb}-\mathrm{F}\left(\mathrm{ab} \mathbf{b}^{\prime}\right)_{2}$}

Intact clinical grade IFX or ADL (designated here as $\mathrm{mAb}$ ) were digested using in-house produced IdeS. Ten milligrams of $\mathrm{mAb}$ was incubated with $300 \mu \mathrm{g}$ of IdeS in the final volume of $500 \mu \mathrm{l} \mathrm{PBS}$ for $2.5 \mathrm{~h}$ at $37^{\circ} \mathrm{C}$, followed by a spike-in of additional $300 \mu \mathrm{g}$ of IdeS to achieve full digestion of the $\mathrm{Fc}$ fragments. IdeS inactivation was carried out by adding $0.1 \mathrm{M}$ of citric acid $\mathrm{pH} 3$ and incubation for $1 \mathrm{~min}$ at RT followed by the addition of PBS ( $\mathrm{pH}$ 7.4) to neutralized acidic $\mathrm{pH}$. Next, reaction mixture was applied to a $1 \mathrm{~mL}$ HiTrap KappaSelect affinity column (GE Healthcare Life Sciences). All affinity purification 
steps were carried out by connecting the affinity column to a peristaltic pump with flow rate of $1 \mathrm{ml} / \mathrm{min}$. The reaction mixture was recycled three times through the KappaSelect column to maximize the capture of intact $\mathrm{mAb}$ and $\mathrm{mAb}-\mathrm{F}\left(\mathrm{ab}^{\prime}\right)_{2}$. KappaSelect column was subsequently washed with $5 \mathrm{CV}$ of PBS and eluted with $10 \mathrm{CV}$ of $100 \mathrm{mM}$ glycine $\mathrm{HCl}(\mathrm{pH} 2.7)$. Collected $1 \mathrm{ml}$ elution fractions were immediately neutralized with $100 \mu$ l of $1.5 \mathrm{M}$ Tris. $\mathrm{HCl}(\mathrm{pH} 8.8)$. Next, the recovered intact $\mathrm{mAb}$ and $\mathrm{mAb}-\mathrm{F}(\mathrm{ab})_{2}$ fragments were applied to a custom packed $1 \mathrm{ml}$ Protein-G agarose column (GenScript). The reaction mixture was recycled three times through the column, which was subsequently washed with $5 \mathrm{CV}$ of PBS and eluted with $10 \mathrm{CV}$ of $100 \mathrm{mM}$ glycine. $\mathrm{HCl}(\mathrm{pH} 2.7)$. The $10 \mathrm{ml}$ elution fraction was immediately neutralized with $1 \mathrm{ml}$ of $1.5 \mathrm{M}$ Tris. $\mathrm{HCl}$ $\left(\mathrm{pH}\right.$ 8.8). The recovered $10 \mathrm{ml} \mathrm{mAb}-\mathrm{F}\left(\mathrm{ab}^{\prime}\right)_{2}$ fragments were dialyzed overnight at $4^{\circ} \mathrm{C}$ against $4 \mathrm{~L}$ of $\mathrm{PBS}(\mathrm{pH}$ 7.4) using SnakeSkin dialysis tubing with $10 \mathrm{kDa}$ cutoff (Thermo Fisher Scientific). Recovered $\mathrm{mAb}-\mathrm{F}(\mathrm{ab})_{2}$ sample were evaluated for purity by SDS-PAGE and their concentration measured by Take 5 (BioTek instruments).

To test the functionality of the produced $\mathrm{mAb}-\mathrm{F}(\mathrm{ab})_{2}, 96$ ELISA plates (Nunc MaxiSorp ${ }^{\mathrm{TM}}$ flat-bottom, Thermo Fisher Scientific) were coated with $1 \mu \mathrm{g} / \mathrm{ml}$ of $\operatorname{rhTNF} \alpha$ in PBS and incubated at $4^{\circ} \mathrm{C}$ O.N. ELISA plates were then washed three times with PBST and blocked with $300 \mu \mathrm{l}$ of $2 \% \mathrm{w} / \mathrm{v}$ BSA in PBS for $1 \mathrm{~h}$ at $37^{\circ} \mathrm{C}$. Next, $50 \mathrm{nM}$ of intact $\mathrm{mAb}$ and $\mathrm{mAb}-\mathrm{F}(\mathrm{ab})_{2}$ (IFX or ADL) in blocking solution was added to each well in triplicates in a 3-fold dilution series, and plates were incubated at RT for $1 \mathrm{~h}$. Next, plates were washed three times with PBST with $30 \mathrm{~s}$ incubation time at each washing cycle. For detection, HRP conjugated anti-human kappa light chain (Jackson) was added to each well ( $50 \mu \mathrm{l}, 1: 5,000$ ratio in $2 \% \mathrm{w} / \mathrm{v}$ BSA in PBS) and incubated for $1 \mathrm{~h}$ at RT, followed by three washing cycles with PBST. Developing was carried out by adding $50 \mu \mathrm{l}$ of TMB and reaction was quenched by adding $0.1 \mathrm{M}$ sulfuric acid. Plates were read using the Epoch Microplate Spectrophotometer ELISA plate reader. To evaluate the purity of the $\mathrm{mAb}-\mathrm{Fa}\left(\mathrm{b}^{\prime}\right)_{2}$ samples (i.e., to make sure there are no traces of intact antibody or Fc fragment in the sample), 96 ELISA plate (Nunc MaxiSorp ${ }^{\mathrm{TM}}$ flat-bottom, Thermo Fisher Scientific) were coated with $5 \mu \mathrm{g} / \mathrm{ml}$ of intact $\mathrm{mAb}$ and $\mathrm{mAb}-\mathrm{F}(\mathrm{ab})_{2}$ in PBS and incubated at $4^{\circ} \mathrm{C}$ O.N. Next, plates were washed three time with PBST and blocked with 300 $\mu l 2 \% \mathrm{w} / \mathrm{v}$ BSA in PBS for $1 \mathrm{~h}$ at $37^{\circ} \mathrm{C}$. Next, plates were washed three times with $300 \mu \mathrm{l}$ PBST, followed by the incubation with HRP conjugated anti-human IgG Fc antibody (Jackson) diluted 1:5,000 in PBST. Developing was carried out by adding $50 \mu \mathrm{l}$ of $\mathrm{TMB}$ and reaction was quenched by adding $0.1 \mathrm{M}$ sulfuric acid. Plates were read using the Epoch Microplate Spectrophotometer ELISA plate reader (BioTek Instruments).

\section{Generation of ADA Standard}

A pool of 17 ADA to IFX positive sera were collected at Sheba Medical Center, and passed through a $2 \mathrm{ml}$ custom packed protein $G$ agarose column (GenScript). The pooled sera was recycled three times over the column, which was subsequently washed with $5 \mathrm{CV}$ of PBS and eluted with $10 \mathrm{CV}$ of $100 \mathrm{mM}$ glycine. $\mathrm{HCl}(\mathrm{pH} 2.7)$. The $10 \mathrm{ml}$ elution fraction was immediately neutralized with $1 \mathrm{ml}$ of $1.5 \mathrm{M}$ Tris $\cdot \mathrm{HCl}(\mathrm{pH} 8.8$ ). The purified mAbs were immediately passed over a custom made $\operatorname{rhTNF} \alpha$ affinity column (NHS-activated agarose beads, Thermo Fisher Scientific) in gravity mode. The purified mAbs were recycled three times over the column, which was subsequently washed with $5 \mathrm{CV}$ of PBS and eluted with $10 \mathrm{CV}$ of $100 \mathrm{mM}$ glycine $\cdot \mathrm{HCl}$ ( $\mathrm{pH}$ 2.7). The $10 \mathrm{ml}$ elution fraction was immediately neutralized with $1 \mathrm{ml}$ of $1.5 \mathrm{M}$ Tris. $\mathrm{HCl}$ ( $\mathrm{pH} 8.8$ ). The purified mAbs were dialyzed overnight at $4^{\circ} \mathrm{C}$ against $4 \mathrm{~L}$ of $\mathrm{PBS}(\mathrm{pH} 7.4)$ using SnakeSkin dialysis tubing with $10 \mathrm{kDa}$ cutoff (Thermo Fisher Scientific). Purified mAbs were analyzed for purity using $12 \%$ SDS-PAGE and concentration was determined by Take 3 (BioTek instruments).

To test functionality, 96 ELISA plate were coated with $5 \mu \mathrm{g} / \mathrm{ml}$ of $\mathrm{mAb}-\mathrm{F}(\mathrm{ab})_{2}$ in PBS (pH 7.4) and incubated at $4^{\circ} \mathrm{C} \mathrm{O.N.} \mathrm{ELISA}$ plates were then washed three times with PBST and blocked with $300 \mu \mathrm{l}$ of $2 \% \mathrm{w} / \mathrm{v}$ BSA in PBS for $1 \mathrm{~h}$ at $37^{\circ} \mathrm{C}$. Next, $50 \mathrm{nM}$ of the purified ADA in blocking solution were added to each well in triplicates with 3-fold dilution series and plates were incubated at RT for $1 \mathrm{~h}$. Next, plates were washed three times with PBST with $30 \mathrm{~s}$ incubation time at each washing cycle. Next, antihuman Fc HRP conjugate (Jackson) was added to each well at the detection phase ( $50 \mu l, 1: 5,000$ ratio in $2 \% \mathrm{w} / \mathrm{v}$ BSA in PBS) and incubated for $1 \mathrm{~h}$ at RT, followed by three washing cycles with PBST. Developing was carried out by adding $50 \mu \mathrm{l}$ of TMB and reaction was quenched by adding $0.1 \mathrm{M}$ sulfuric acid. Plates were read using the Epoch Microplate Spectrophotometer ELISA plate reader.

\section{Quantitative Measurement of ADA in Serum}

The schematic configuration of the bio-immunoassay for the quantitative measurement of ADA in serum is described in Figure $3 \mathbf{B}$ and was carried out as follows: ELISA plates that were coated overnight at $4^{\circ} \mathrm{C}$ with $5 \mu \mathrm{g} / \mathrm{ml}$ produced IFX-F $(\mathrm{ab})_{2}$ in PBS ( $\mathrm{pH} 7.4$ ). ELISA plates were then washed three times with PBST and blocked with $300 \mu \mathrm{l}$ of $2 \% \mathrm{w} / \mathrm{v}$ BSA in PBS for $1 \mathrm{~h}$ at $37^{\circ} \mathrm{C}$. Next, triplicates of 1:400 diluted serum samples were added at triplicates and serially diluted 2 -fold in $2 \% \mathrm{w} / \mathrm{v}$ BSA in PBS, $10 \%$ horse serum (Biological Industries) and 1\% Tween 20 in PBS (1:400- 1:51,200 serum dilution factor). Plates were incubated for $1 \mathrm{~h}$ at RT. On the same plate, serial dilutions of $10 \mathrm{nM}$ ADA standard were incubated in triplicate and serially diluted 2-fold in $2 \% \mathrm{w} / \mathrm{v}$ BSA in PBS, $10 \%$ horse serum (Biological Industries) and $1 \%$ Tween 20 in PBS, to allow the conversion of the tested serum to units per milliliter. ELISA plates were washed three times with PBST and $50 \mu \mathrm{l}$ of HRP conjugated anti-human IgG Fc was added to each well (50 $\mu \mathrm{l}, 1: 5,000$ ratio in $2 \% \mathrm{w} / \mathrm{v}$ BSA in PBS) and incubated for $1 \mathrm{~h}$ at RT. ELISA plate was then washed three times with PBST and developed by adding $50 \mu \mathrm{l}$ of TMB followed by quenching with $50 \mu \mathrm{l} 0.1 \mathrm{M}$ sulfuric acid. Plates were read using the Epoch Microplate Spectrophotometer ELISA plate reader.

\section{Neutralization Index of ADA}

Neutralization capacity was determined using ELISA plates that were coated overnight at $4^{\circ} \mathrm{C}$ with $5 \mu \mathrm{g} / \mathrm{ml}$ IFX-F $\left(\mathrm{ab}^{\prime}\right)_{2}$ in PBS ( $\mathrm{pH}$ 7.4). Next, coating solution was discarded and ELISA plates 
were blocked with $300 \mu \mathrm{l}$ of $2 \% \mathrm{w} / \mathrm{v}$ BSA in PBS for $1 \mathrm{~h}$ at $37^{\circ} \mathrm{C}$. Blocking solution was discarded and $50 \mu \mathrm{l}$ of $200 \mathrm{nM}$ rhTNF $\alpha$ in $2 \% \mathrm{w} / \mathrm{v}$ BSA were added to the positive rhTNF $\alpha$ wells, and $2 \%$ $\mathrm{w} / \mathrm{v}$ BSA in PBS was added to the negative rhTNF $\alpha$ wells for $1 \mathrm{~h}$ at RT. Next, triplicates of 1:400 diluted serum samples with/without $200 \mathrm{nM}$ rhTNF $\alpha$ were added to the positive/negative $\operatorname{rhTNF} \alpha$ wells, respectively, and serially diluted 2 -fold in $2 \% \mathrm{w} / \mathrm{v}$ BSA, $10 \%$ horse serum (Biological Industries) and 1\% Tween 20 in PBS (1:400-1:51,200 serum dilution factor). Plates were incubated for $1 \mathrm{~h}$ at RT. ELISA plates were washed three times with PBST and $50 \mu \mathrm{l}$ of HRP conjugated anti-human IgG Fc antibody or anti HRP conjugated His-tag antibody were added at the detection phase $(50 \mu l, 1: 5,000$ ratio in $2 \% \mathrm{w} / \mathrm{v}$ BSA in PBS) and incubated for $1 \mathrm{~h}$ at RT, followed by three washing cycles with PBST. Developing was carried out by adding $50 \mu \mathrm{l}$ of TMB and reaction was quenched by adding $0.1 \mathrm{M}$ sulfuric acid. Plates were read using the Epoch Microplate Spectrophotometer ELISA plate reader.

Neutralization index was calculated as following: an ELISA equation curve was calculated separately for wells with and without $\operatorname{rhTNF} \alpha$, using the GraphPad Prism software. The average triplicate signal which are $3 \times$ standard deviation above the background signal was substituted in the ELISA equation curve to extract the serial dilution value. The logarithmic difference of the value with/without $\operatorname{rhTNF} \alpha$ represents the neutralization index.

\section{Blood Processing}

IFX treated patients with IBD cared for in the Department of Gastroenterology at the Sheba medical center were included in the study. All subjects signed an informed consent, and the study was approved by the Ethics Committee of the medical center. All patients received IFX on a scheduled regimen and blood samples were drawn immediately before their scheduled IFX infusion. Blood was collected into a single Vacutainer Lithium Heparin collection tube (BD Bioscience).

For NGS analysis, blood was collected from a male donor treated with IFX, before IFX administration and 10 days after administration. Thirty milliliters of peripheral blood were collected into 3 single Vacutainer K-EDTA collection tubes (BD Biosciences). Collection of peripheral blood mono-nuclear cells (PBMCs) was performed by density gradient centrifugation, using Uni-SepMAXI+ lymphocyte separation tubes (Novamed) according to the manufacturer's protocol.

\section{Fluorescence-Activated Cell Sorting Analysis and Sorting of B Cell Populations}

PBMCs were stained for $15 \mathrm{~min}$ in cell staining buffer (BioLegend) at RT in the dark using the following antibodies: anti-CD3-PerCP (clone OKT3; BioLegend), anti-CD19Brilliant Violet 510 (clone HIB19; BioLegend), anti-CD27-APC (clone O323; BioLegend), anti-CD38-APC-Cy7 (clone HB-7; BioLegend), and anti-CD20-FITC (clone 2H7; BioLegend).

The following $\mathrm{B}$ cell population was sorted using a FACSAria cell sorter (BD Bioscience): CD3-CD19+CD20CD27++CD38 high .
B cell subpopulations were sorted and collected into TRI Reagent solution (Sigma Aldrich) and frozen at $-80^{\circ} \mathrm{C}$.

\section{Amplification of $V_{H}$ and $V_{L}$ Repertoires From B Cells}

Total RNA was isolated using RNeasy micro Kit (Qiagen), according to manufacturer's protocol. First-strand cDNA generation was performed with $100 \mathrm{ng}$ of isolated total RNA using a SuperScript RT II kit (Invitrogen) and oligo-dT primer, according to manufacturer's protocol. After cDNA synthesis, PCR amplification was performed to amplify the $V_{H}$ and $V_{L}$ genes using a primer set described previously (23) with overhang nucleotides to facilitate Illumina adaptor addition during the second PCR (Table S1). PCR reactions were carried out using FastStart ${ }^{\mathrm{TM}}$ High Fidelity PCR System (Roche) with the following cycling conditions: $95^{\circ} \mathrm{C}$ denaturation for $3 \mathrm{~min} ; 95^{\circ} \mathrm{C}$ for $30 \mathrm{~s}$, $50^{\circ} \mathrm{C}$ for $30 \mathrm{~s}$, and $68^{\circ} \mathrm{C}$ for $1 \mathrm{~min}$ for four cycles; $95^{\circ} \mathrm{C}$ for $30 \mathrm{~s}, 55^{\circ} \mathrm{C}$ for $30 \mathrm{~s}$, and $68^{\circ} \mathrm{C}$ for $1 \mathrm{~min}$ for four cycles; $95^{\circ} \mathrm{C}$ for $30 \mathrm{~s}, 63^{\circ} \mathrm{C}$ for $30 \mathrm{~s}$, and $68^{\circ} \mathrm{C}$ for $1 \mathrm{~min}$ for 20 cycles; and a final extension at $68^{\circ} \mathrm{C}$ for $7 \mathrm{~min}$. PCR products were purified using AMPure XP beads (Beckman Coulter), according to manufacturer's protocol (ratio $\times 1.8$ in favor of the beads). Recovered DNA products from the first PCR was applied to a second PCR amplification to attach Illumina adaptors to the amplified $V_{H}$ and $V_{L}$ genes using the primer extension method as described previously (24). PCR reactions were carried out using FastStart ${ }^{\mathrm{TM}}$ High Fidelity PCR System (Roche) with the following cycling conditions: $95^{\circ} \mathrm{C}$ denaturation for $3 \mathrm{~min}$; $95^{\circ} \mathrm{C}$ for $30 \mathrm{~s}, 40^{\circ} \mathrm{C}$ for $30 \mathrm{~s}$, and $68^{\circ} \mathrm{C}$ for $1 \mathrm{~min}$ for two cycles; $95^{\circ} \mathrm{C}$ for $30 \mathrm{~s}, 65^{\circ} \mathrm{C}$ for $30 \mathrm{~s}$, and $68^{\circ} \mathrm{C}$ for $1 \mathrm{~min}$ for $7 \mathrm{cycles}$; and a final extension at $68^{\circ} \mathrm{C}$ for $7 \mathrm{~min}$. PCR products were applied to $1 \%$ agarose DNA gel electrophoresis and gel-purified with Zymoclean ${ }^{\mathrm{TM}}$ Gel DNA Recovery Kit (Zymo Research) according to the manufacturer's instructions. $V_{H}$ and $V_{L}$ libraries concentration were measured using Qubit system (Thermo Fisher Scientific) and library quality was assessed using the Bioanalyzer 2100 system (Agilent) or the 4200 TapeStation system (Agilent). All $\mathrm{V}_{\mathrm{H}}$ libraries were produced in duplicates starting with RNA as the common source template. The $\mathrm{V}_{\mathrm{L}}$ were produced with one replicate.

$\mathrm{V}_{\mathrm{H}}$ and $\mathrm{V}_{\mathrm{L}}$ libraries from sorted $\mathrm{B}$ cell were subjected to NGS on the MiSeq platform with the reagent kit V3 $2 \times 300$ bp paired-end (Illumina), using an input concentration of $16 \mathrm{pM}$ with 5\% PhiX.

Raw fastq files were processed using our recently reported ASAP webserver (25). ASAP analysis resulted in a unique, fulllength $V_{H}$ and $V_{L}$ gene sequences database for each time point. The resultant database was used as a reference database to search the LC-MS/MS spectra.

\section{Proteomic Analysis of the Serum ADA to IFX}

Total IgG from each time point (D0, D10) were purified from 7 to $10 \mathrm{ml}$ of serum by protein $\mathrm{G}$ enrichment. Serum was diluted 2-fold and passed through a $5 \mathrm{ml}$ Protein $\mathrm{G}$ agarose column (GeneScript). The diluted serum was recycled three times over 
the column, which was subsequently washed with $10 \mathrm{CV}$ of PBS and eluted with $7 \mathrm{CV}$ of $100 \mathrm{mM}$ glycine. $\mathrm{HCl}$ ( $\mathrm{pH} 2.7)$. A total of 35 fractions of $1 \mathrm{ml}$ were collected and immediately neutralized with $100 \mu \mathrm{l}$ of $1.5 \mathrm{M}$ Tris. $\mathrm{HCl}(\mathrm{pH} 8.8)$. All elution fractions were evaluated for their purity using $12 \%$ SDS-PAGE and 11 purified $1 \mathrm{ml} \mathrm{IgG}$ fractions were combined and dialyzed overnight at $4^{\circ} \mathrm{C}$ against $4 \mathrm{~L}$ of PBS (pH 7.4) using SnakeSkin dialysis tubing with $1 \mathrm{kDa}$ cutoff (Thermo Fisher Scientific).

Next, $9 \mathrm{mg}$ of total IgG were digested with $100 \mu \mathrm{g}$ of IdeS in the final volume of $2 \mathrm{ml} \mathrm{PBS}$ for $5 \mathrm{~h}$ at $37^{\circ} \mathrm{C}$. IdeS inactivation was carried out by adding $0.1 \mathrm{M}$ of citric acid $\mathrm{pH} 3$ and incubation for 1 min at RT followed by the addition of PBS ( $\mathrm{pH} 7.4$ ) to neutralize the low $\mathrm{pH}$. Total serum $\mathrm{F}\left(\mathrm{ab}^{\prime}\right)_{2}$ was then applied to a one $\mathrm{ml}$ custom made affinity column comprised of IFX-F(ab') $)_{2}$ coupled to NHS-activated agarose beads (Thermo Fisher Scientific). The purified serum $\mathrm{F}\left(\mathrm{ab}^{\prime}\right)_{2}$ were recycled three times over the affinity column, which was subsequently washed with $5 \mathrm{CV}$ of PBS and eluted with $15 \mathrm{CV}$ of $100 \mathrm{mM}$ glycine. $\mathrm{HCl}(\mathrm{pH} 2.7)$ and collected into Maxymum Recovery Eppendorf (Axygen Scientific). A total of $30 \times 0.5 \mathrm{ml}$ elution fractions and $1 \times 50 \mathrm{ml}$ flow-through were immediately neutralized with 50 and $100 \mu \mathrm{l}$, respectively, of $1.5 \mathrm{M}$ Tris $\cdot \mathrm{HCl}(\mathrm{pH} 8.8)$. The purified antigen-specific $\mathrm{F}(\mathrm{ab})_{2}$ were dialyzed overnight at $4^{\circ} \mathrm{C}$ against $4 \mathrm{~L}$ of PBS (pH 7.4) using SnakeSkin dialysis tubing with $10 \mathrm{kDa}$ cutoff (Thermo Fisher Scientific). Elution and flow-through fractions were trypsindigested, and resulting peptides were fractionated and sequenced by nanoflow LC-electrospray MS/MS on an Orbitrap Velos Pro hybrid mass spectrometer (Thermo Scientific), in the UT Austin mass spectrometry core facility as described previously (26). MS/MS raw files were analyzed by MaxQuant software version 1.6.0.16 (27) using the MaxLFQ algorithm (28) and peptide lists were searched against the common contaminants database by the Andromeda search engine (29) and a custom protein sequence database consisting of the donor-specific $V_{H}$ and $V_{L}$ sequences derived from NGS of individual donor B cells. All searches were carried out with cysteine carbamidomethylation as a fixed modification and methionine oxidations as variable modifications. The false discovery rate was set to 0.01 for peptides with a minimum length of seven amino acids and was determined by searching a reverse decoy database. Enzyme specificity was set as C-terminal to arginine and lysine as expected using trypsin as protease, and a maximum of two missed cleavages were allowed in the database search. Peptide identification was performed with an allowed initial precursor mass deviation up to $7 \mathrm{ppm}$ and an allowed fragment mass deviation of $20 \mathrm{ppm}$. For LFQ quantification the minimal ratio count was set to 2 , and match between runs was performed with three mass-spec injections originating from the same sample. MaxQunat output analysis file, "peptides.txt," was used for further processing. Total peptides that were identified in the elution samples were filtered using the following criteria: (a) were not identified as contaminates; (b) did not match to the reversed decoy database; (c) were identified as peptides derived from the region comprising the CDRH3, J region, FR4 and the ASTK motif (derived from the $\mathrm{N}$-terminal of the $\mathrm{C}_{\mathrm{H}} 1$ region). The $\mathrm{CDRH} 3$ derived peptides were further characterized as informative CDRH3 peptides (iCDRH3 peptides) only if they map exclusively to a single antibody clonotype. A clonotype was defined as all sequences that comprise CDRH3 with the same length and identity tolerating one amino acid mismatch, and same V, J family. The intensities of high confidence iCDRH3 peptides were averaged between replicates while including only peptides that were observed in at least two out of the three replicates. Clonotype frequencies within each sample were calculated using only $i \mathrm{CDRH} 3$ peptides and were determined to be antigen-specific if their frequency in the elution fraction was at least 5 -fold greater than their frequency in the flow-through fraction. The CDRH3 sequences identified by the mapping of high confidence MS/MS peptides were used to generate a complete list of full length $\mathrm{VH}$ sequences. These $\mathrm{VH}$ sequences were used to analyze the repertoire measures of the antibodies that were identified in the donors' serum.

Same filtering criteria was applied to peptides derived from the constant region of both $\kappa$ and $\lambda$ light chains. By quantifying the accumulative intensities of these peptides, we calculated the ratio of $\kappa: \lambda$ light chain from antibodies that were derived from the affinity column elution fraction which represent both $n t \mathrm{ADA}$ and $b \mathrm{ADA}$, and in the affinity column flow through fraction which represent the depleted ADA fraction.

\section{Study Population}

IFX and ADL treated patients with IBD cared for in the Departments of Gastroenterology at Sheba medical center were included in the study. All subjects signed an informed consent, and the study was approved by the Ethics Committee of Sheba medical center. IFX and ADL and ADA serum levels were routinely measured at trough immediately before infusion. All patients received IFX and ADL on a scheduled regimen. All patients that were included in this study exhibited low through levels of IFX and ADL.

\section{Statistical Analysis}

All curves were fitted on a sigmoidal dose-response curve and EC50 of each was calculated. Mann-Whitney test was used to compare continuous variables. All reported $P$-values were twotailed, and a $P<0.05$ were considered statistically significant. All statistics were performed with GraphPad Prism software (version 7, San Diego, California).

\section{RESULTS}

\section{Production of $\left.\mathrm{mAb}-\mathrm{F}(\mathrm{ab})^{\prime}\right)_{2}$ to $\mathrm{Be}$ Used in the Bio-Immunoassay}

To investigate the molecular landscape of $\mathrm{ADA}$ following $\mathrm{mAb}$ administration we first aimed to develop an accurate, sensitive, robust bio-immunoassay to determine ADA levels in sera. The working hypothesis was that anti-idiotypic antibodies dominate the ADA compartment (21) thus, the developed bioimmunoassay was based on the drugs' $\mathrm{F}(\mathrm{ab})_{2}$ portion to be used as the antigen (i.e., coating agent).

To achieve this, we used the immunoglobulin G (IgG)cleaving enzyme (IdeS), a cysteine proteinase enzyme that proteolytically cleaves immunoglobulins below the hinge region [(30); Figure 1A]. IFX was digested using IdeS by incubating $10 \mathrm{mg}$ of clinical grade $\mathrm{mAb}$ with IdeS to reach near complete 
A

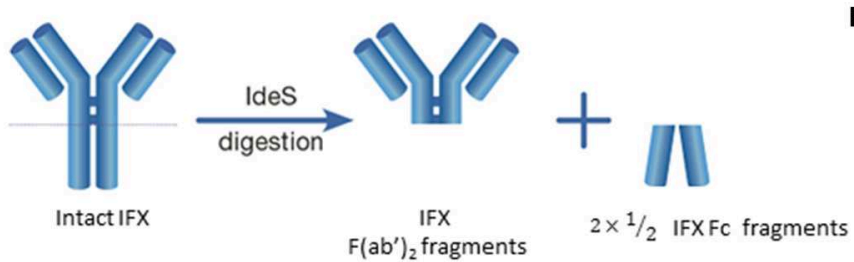

B

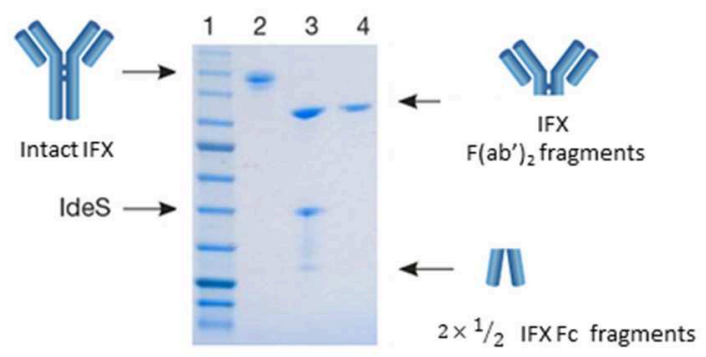

C

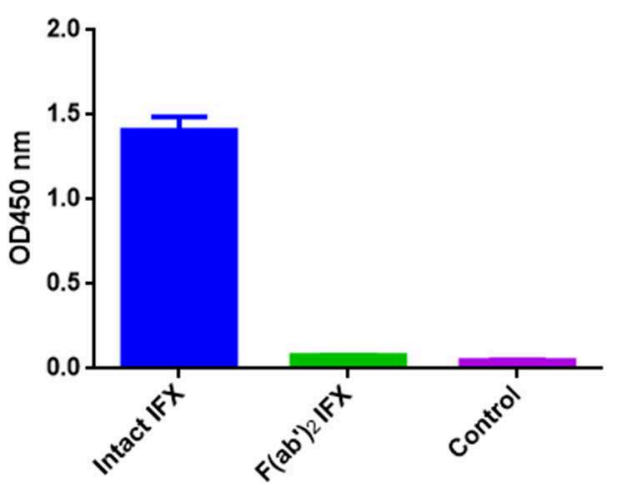

D

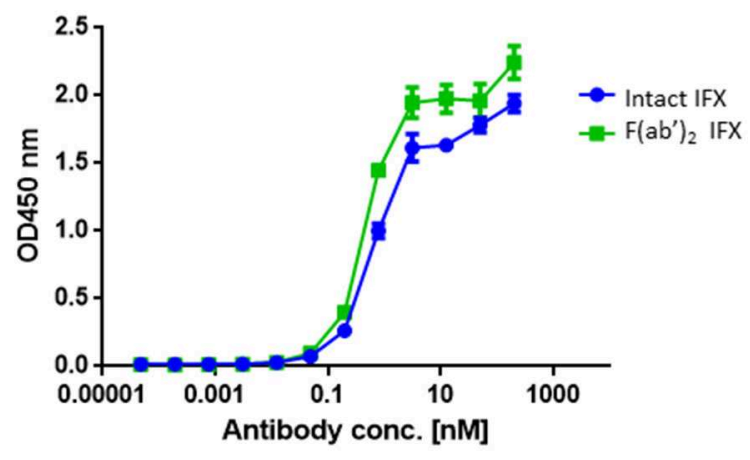

FIGURE 1 | IFX digestion and IFX-F(ab') 2 purification. (A) Schematic representation of IgG digestion with IdeS. IdeS is a highly specific immunoglobulin-degrading enzyme that cleaves below the disulfide bonds in the lgG hinge region. The cleavage results in the production of IFX-F(ab') ${ }_{2}$ fragment and two $1 / 2$ FC fragments. (B) SDS-PAGE analysis of intact IgG (lane 2), following IdeS digestion (lane 3) and purified IFX-F(ab') 2 following a 2-step affinity chromatography purification including protein A and kappa-select columns (lane 4). (C) Presence of Fc and intact IgG traces was measured by direct ELISA where intact IFX and purified IFX-F(ab') 2 were compared to a control antigen (streptavidin) as coating agents followed by direct incubation with an anti-Fc HRP conjugate at the detection phase. (D) The functionality of the recovered IFX-F(ab') $)_{2}$ was confirmed by testing it for TNF $\alpha$ binding by ELISA in comparison to intact IFX. The ELISA setup included TNF $\alpha$ as the coating agent and anti-Fc HRP conjugate at the detection phase. For (C,D), triplicate averages were calculated as mean, with error bars indicating s.d.

digestion. Next, IFX-F(ab') $)_{2}$ was purified from Fc regions and undigested full IFX by consecutive affinity chromatography steps comprising protein A and kappaSelect columns.

Recovered IFX-F(ab') $)_{2}$ purity was evaluated by SDS-PAGE (Figure 1B) and ELISA (Figure 1C) to ensure that the IFX$\mathrm{F}(\mathrm{ab})_{2}$ exhibits no traces of IFX-Fc/undigested IFX that will contribute to the background level when using anti-Fc HRP conjugate at the detection phase. Recovered IFX-F $(\mathrm{ab})_{2}$ samples were found to be highly pure with basal anti-Fc signal levels similar to the signal observed in the control samples. The produced IFX-F $\left(a b^{\prime}\right)_{2}$ was tested for functionality by measuring its $\mathrm{TNF} \alpha$ binding capacity, using ELISA with $\mathrm{TNF} \alpha$ as the coating agent, and was found to show similar functionality as that of the intact IFX (Figure 1D). ADL was subjected to the same preparative pipeline and demonstrated similar results (Figure S1).

\section{ADA Standard Curve}

Quantification of total ADA in serum requires a standard reference. Thus, we generated a standard ADA pool that facilitates the quantification of ADA levels in sera of patient treated with IFX. ADA were pooled from several serum samples collected from patients treated with IFX and purified by consecutive affinity chromatography steps comprising protein $\mathrm{G}$ and a custom-made IFX-F(ab') $)_{2}$ affinity columns. We confirmed the affinity enrichment of ADA by applying the affinity chromatography elution fraction to ELISA with IFX-F(ab') $)_{2}$ as the coated antigen (Figure 2A). The purity and concentration the recovered ADA were determined by SDS-PAGE (Figure 2B) and nanodrop.

Maximal serum concentration used in a bio-immunoassay (e.g., serum diluted 1:100 or 1:200) is a major factor that may contribute to high background signal levels due to non-specific binding. Screening several maximal serum dilutions showed that 1:400 initial serum dilution demonstrates the lowest background signal (data not shown). To evaluate if serum will affect the signal obtained from purified ADA, we spiked-in purified ADA into negative control serum that was diluted 1:400 in PBS. Serial dilution of spiked-in ADA and purified ADA showed similar signal in ELISA (Figure 2C) indicating that serum does not bias the ADA detection in our developed bio-immunoassay.

\section{Quantitative Measurement of ADA in Serum}

ADA detection is technically challenging as both the analyte and antigen are antibodies which may result in the inability 

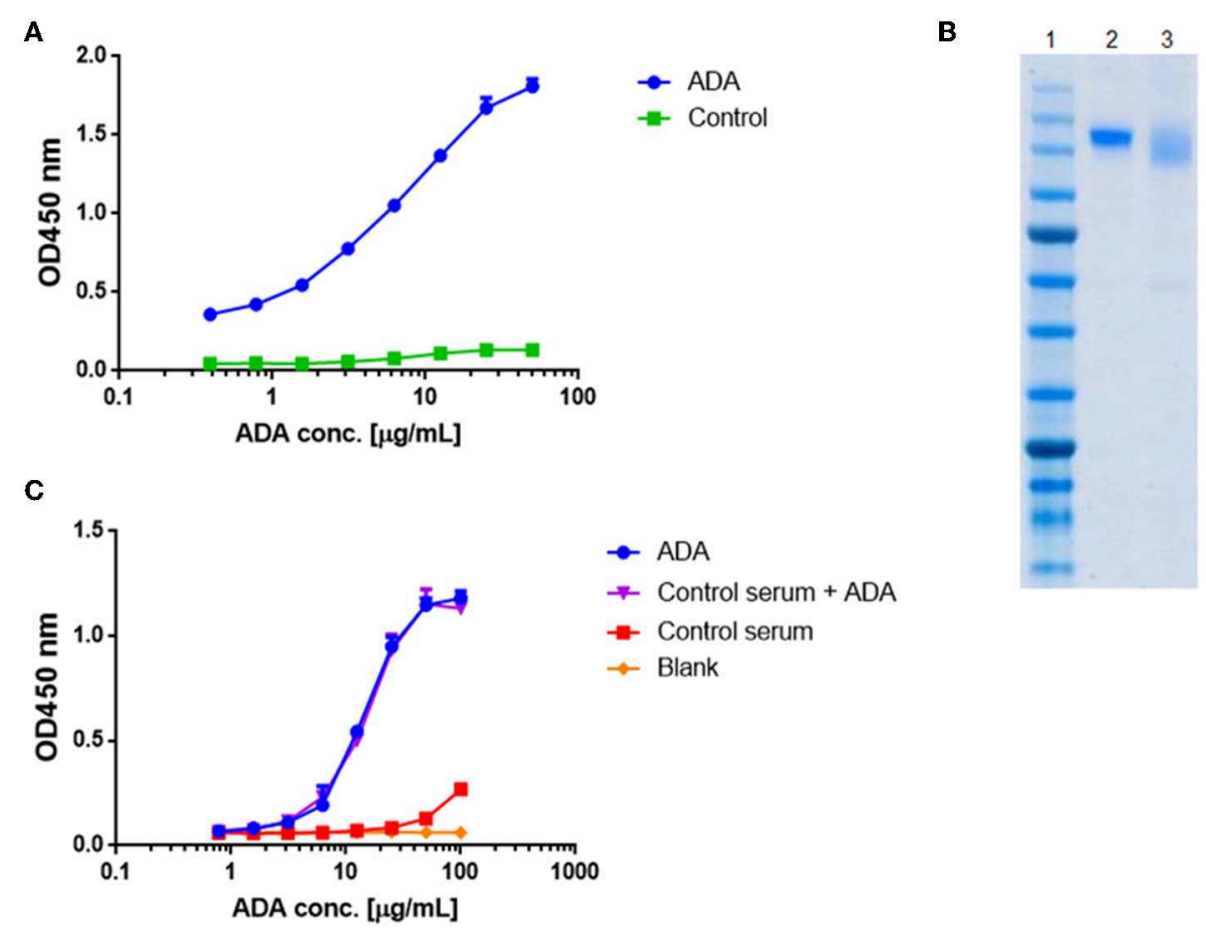

FIGURE 2 | Standard curve for ADA quantification in patients treated with IFX. ADA were purified from sera of 17 patients treated with IFX, utilizing consecutive affinity chromatography steps including protein $\mathrm{G}$ and custom made IFX-F(ab') ${ }_{2}$ columns. (A) Purified ADA were tested in ELISA for functionality. TNF $\alpha$ was used as the coating agent followed by incubation with purified ADA and anti-Fc HRP conjugate at the detection phase. Control included serum obtained from a healthy donor. (B) SDS-PAGE analysis of intact IFX (lane 2) and purified ADA (lane 3). (C) The effect of serum on ADA standard was tested in ELISA by s piking-in differential concentrations of ADA into ADA negative serum.

to differentiate between the $\mathrm{mAb}$ and ADA. To overcome this challenge, many assays were previously developed (5). One of these immunoassays is the anti-human $\lambda$ chain (AHLC) immunoassay that is used in clinical setups for monitoring the formation of ADA (31). The principle of this assay is to detect ADA comprising $\lambda$ light chain, thus avoiding cross reactivity with the drug that comprises the $\kappa$ light chain (Figure 3A).

While AHLC is suitable for monitoring the development of ADA in clinical setups, when one aims to study the molecular composition of ADA there is a need to provide quantitative measures of total ADA in serum. Thus, we developed a new bioimmunoassay based on the $\mathrm{F}\left(\mathrm{ab}^{\prime}\right)_{2}$ portion of the $\mathrm{mAb}$. The bioimmunoassay setup is described in Figure $\mathbf{3 B}$ and is based on $\mathrm{mAb}-\mathrm{F}(\mathrm{ab})_{2}$ as the coating antigen and anti-Fc HRP conjugate used as the detection antibody. Each of the experimental setups to test ADA in serum included serum from a healthy donor as a control and ADA standard for the quantitation of total ADA.

First, we applied the newly developed bio-immunoassay on two serum sample groups: one negative and one positive for ADA as determined by the AHLC assay $\left[\mathrm{AHLC}^{(-)}\right.$and $\mathrm{AHLC}^{(+)}$, respectively]. We also included serum from a healthy subject to serve as a control for the assay specificity (i.e., serum from a subject that was not exposed to IFX). As shown in Figures 3C,D, the ELISA signals obtained when utilizing the new bio-immunoassay were higher compared to the signal obtained with the AHLC assay. Moreover, applying the new bioimmunoassay on the AHLC ${ }^{(-)}$serum (no detected ADA with the AHLC assay) detected relatively high levels of ADA. These results indicate that not all ADA were detected with the AHLC assay as this assay is based on the detection of ADA that comprise the $\lambda$ light chain only.

Next, to extend and generalize the above results, sera from 54 patients treated with IFX were collected at the Chaim Sheba Medical Center and tested for drug levels and ADA using the AHLC assay. The established cohort showed very low drug trough levels and based on the AHLC results, sera were stratified into two groups: 25 serum samples were identified as $\mathrm{AHLC}^{(-)}$and 29 as $\mathrm{AHLC}^{(+)}$. Using our newly developed quantitative bio-immunoassay, we found that ADA levels in tested sera ranged between 1.82 and $1268.5 \mu \mathrm{g} / \mathrm{ml}$. Serum ADA levels using AHLC compared to the new bioimmunoassay are summarized in Table 1. More importantly, the new bio-immunoassay demonstrated improved sensitivity compared to AHLC assay manifested in the detection of higher concentrations of ADA in 46 out of the 54 serum samples, of which 17 out of the 54 samples, belong to the AHLC $^{(-)}$group. Overall, the average fold increase in ADA detection using the new bio-immunoassay compared to the AHLC assay was 14.13 and 53.26 for the $\mathrm{AHLC}^{(+)}$and $\mathrm{AHLC}^{(-)}$ groups, respectively. 
A

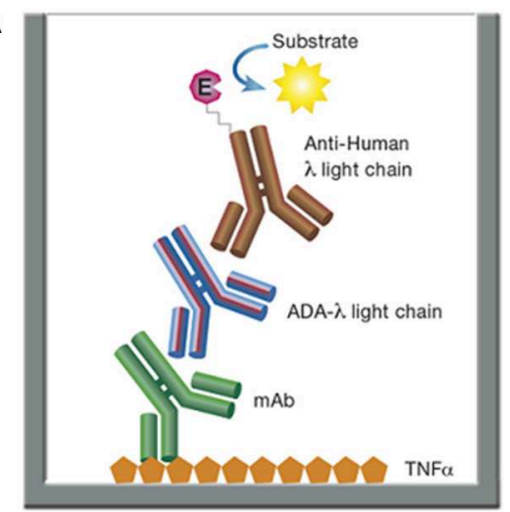

C

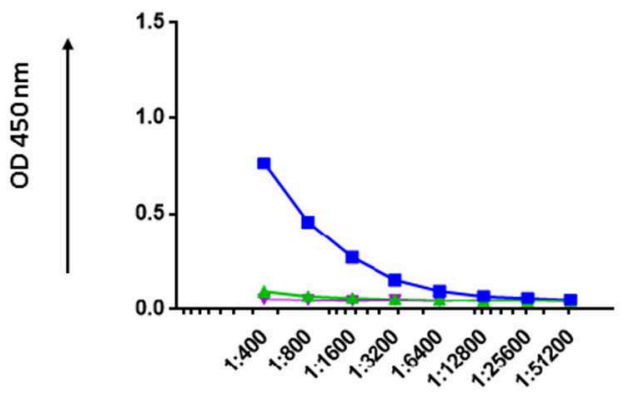

B

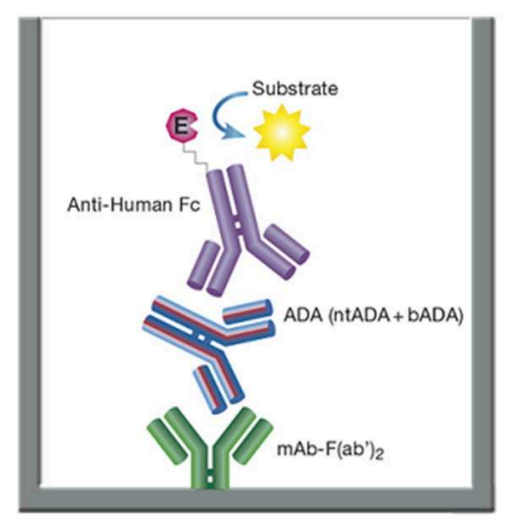

D

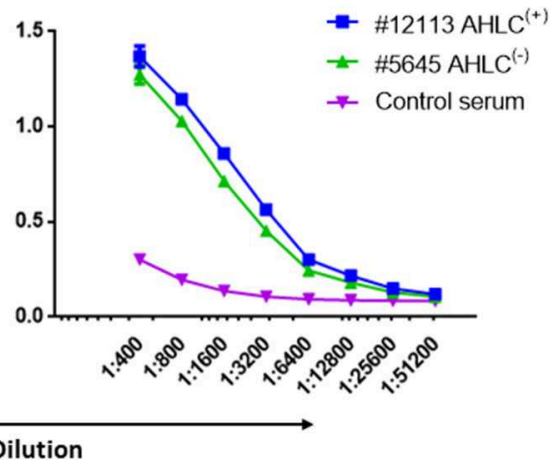

FIGURE 3 | AHLC and the newly developed mAb-F(ab')2 based bio-immunoassay configuration and their application on serum samples from patients treated with IFX. (A) AHLC assay is based on an ELISA where TNF $\alpha$ is used as the coating agent, following the incubation with the mAb drug followed by serial dilutions of the tested sera. anti- $\lambda$ HRP conjugate is used at the detection phase. (B) The newly developed mAb-F(ab') 2 based bio-immunoassay configuration. The assay is based on an ELISA where mAb-F(ab') $)_{2}$ is used as the coating agent followed by serial dilutions of the tested sera. Anti-Fc HRP conjugate is used at the detection phase. (C) ELISA obtained by utilizing the AHLC assay on two serum samples. Using this assay, one of the tested sera showed detectable levels of ADA [AHLC ${ }^{(+)}$] and one had no detectable levels of ADA [AHLC $\left.{ }^{(-)}\right]$. (D) Both serum samples were tested by the newly developed mAb-F(ab') 2 based bio-immunoassay. This assay was able to detect ADA in both sera. For (C,D), averages were calculated as mean from triplicates, with error bars indicating s.d.

\section{Neutralization Index of ADA}

Due to high clinical relevance and different mechanism of action of $b \mathrm{ADA}$ and $n t \mathrm{ADA}$, identifying their relative abundances in serum can provide valuable insights regarding the nature of the immune response following $\mathrm{mAb}$ administration. We therefore modified our newly developed $\mathrm{mAb}-\mathrm{F}(\mathrm{ab})_{2}$ based bioimmunoassay by blocking the coated IFX-F $\left(\mathrm{ab}^{\prime}\right)_{2}$ binding site with $\mathrm{TNF} \alpha$ in order to obtain a differential signal compared to the unblocked assay (Figure 4A). In order to block the binding site of IFX-F(ab') $)_{2}$ toward TNF $\alpha$ and prevent the binding of antiidiotypic ADA (i.e., ntADA) to the drug, recombinant human $\mathrm{TNF} \alpha(\mathrm{rhTNF} \alpha)$ fused to a His-tag was cloned and expressed (see Materials and Methods). In-house production of rhTNF $\alpha$ was essential, as the $\mathrm{N}$ terminal His-tag was used for monitoring the presence of the rhTNF $\alpha$ throughout the bio-immunoassay.

First, we evaluated the ability of rhTNF $\alpha$ to inhibit the binding of ADA to the coated IFX-F(ab') ${ }_{2}$ by setting up a competitive ELISA where a series of ADA standard concentrations were incubated with a series of fixed $r$ TNF $\alpha$ concentrations (data no shown). We observed a competitive effect while rhTNF $\alpha$ was fixed at the concentration of $5 \mathrm{nM}$ (Figure 4B). This step was important as it enabled us to determine the ADA equimolar concentration of $\operatorname{rhTNF} \alpha$ to be used that will fully occupy the IFX-F(ab' $)_{2}$ binding site and will prevent the binding of $n t$ ADA to the coated (and blocked) IFX-F(ab') ${ }_{2}$. We monitored the presence of rhTNF $\alpha$ using an HRP-conjugated anti-His tag antibody and observed that if we aim to completely block ADA it is required to use equimolar concentration of rhTNF $\alpha$ that is corresponds to the highest concentration of ADA in the assay $(200 \mathrm{~nm})$.

In practice, IFX-F $\left(\mathrm{ab}^{\prime}\right)_{2}$ binding site was blocked with $\operatorname{rhTNF} \alpha$ by prior incubation of serum with the coated IFX-F $(a b)_{2}$ hence, the differential signal $\mathrm{w} /$ and w/o the presence of $\operatorname{rhTNF} \alpha$ represent the portion of ADA that could not bind the IFX$\mathrm{F}(\mathrm{ab})_{2}$ binding site thus, reflects the neutralization capacity (hereby named neutralization index) of the ADA in the tested serum. Using this assay, we evaluated the neutralization index of the $46 \mathrm{ADA}$ positive sera from patients treated with IFX and 7 ADA positive sera from patients treated with ADL. In sera from patients treated with IFX, we noticed that there are two main neutralization index patterns: those with high differential signal (Figure 5A) and low differential signal (Figure 5B). More interestingly, we found that patients that were 
TABLE 1 | ADA concentrations in 54 serum samples from patients treated with IFX.

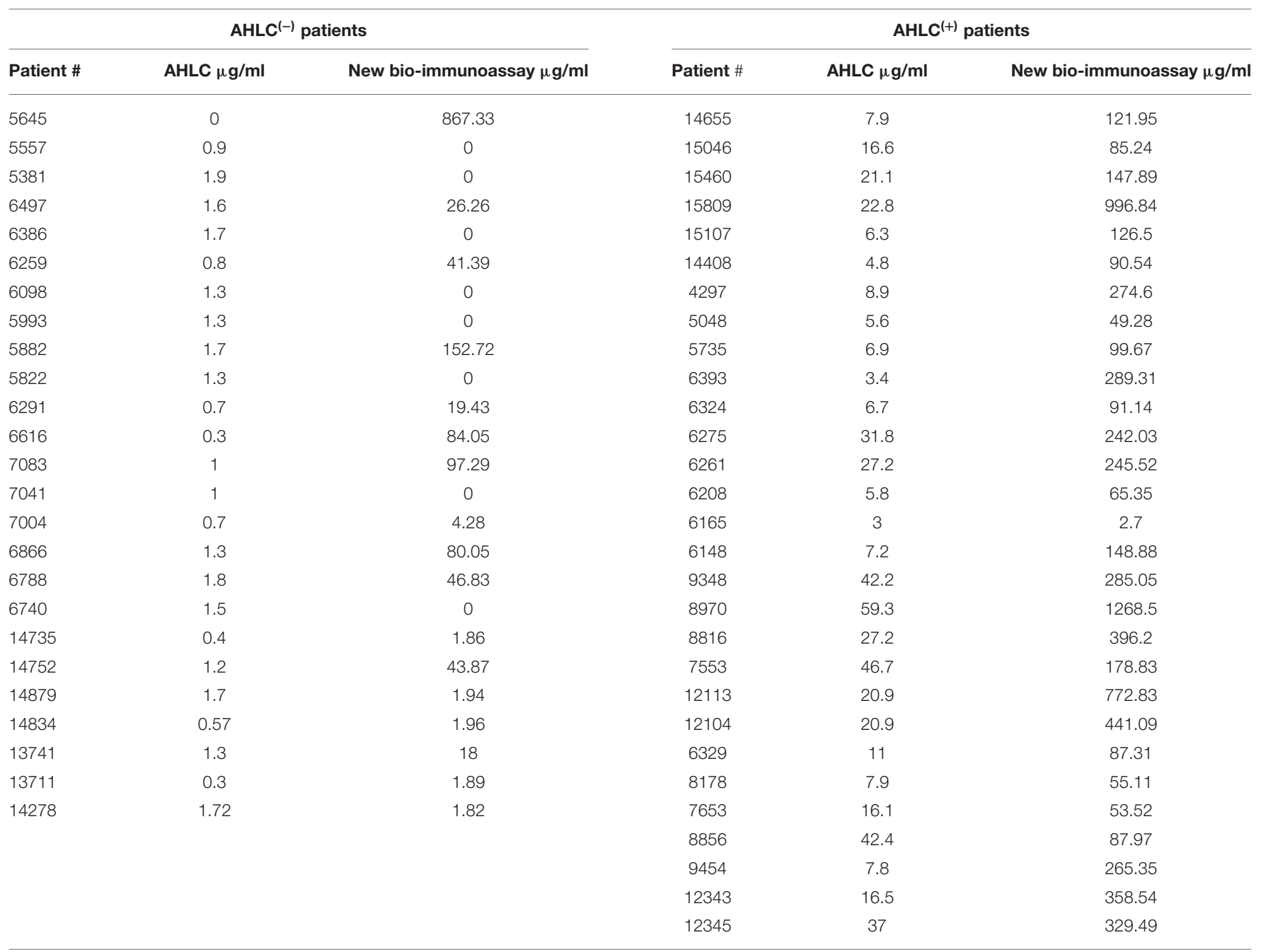

Serum samples were initially stratified into $A H L C^{(+)}$and $A H L C^{(-)}$based on the AHLC assay used in the clinic.

The newly developed bio-immunoassay for the quantification of total ADA was applied on all serum samples and concentration are listed. All ADA concentrations are in $\mu \mathrm{g} / \mathrm{ml}$.

stratified as $\mathrm{AHLC}^{(+)}$have a significantly higher neutralization index compared to those that belong to the $\mathrm{AHLC}^{(-)}$group (Figure 5C). This suggests that there is a preferential usage of the $\lambda$ light chain in $n t \mathrm{ADA}$ as the $\mathrm{AHLC}^{(+)}$group is a priori defined by the presence of ADA comprising the $\lambda$ light chains. All sera from patients treated with ADL $(n=7)$ were subjected to modified bio-immunoassay and demonstrated high neutralization indexes (Figure S2)

\section{IFX Infusion Induces a Vaccine Like Immune Response}

To further investigate the molecular landscape of ADA we explored the dynamics of the $B$ cell response following $\mathrm{mAb}$ administration. When investigating well-controlled clinical scenarios such as samples obtained from post-vaccinated individuals, it is convenient to isolate the antigen-specific $B$ cell as they peak at a defined time window $(23,32)$. However, the characteristics of the humoral response and ADA encoding B cell dynamics following $\mathrm{mAb}$ administration is unknown. Our working hypothesis assumed that the immune response following $\mathrm{mAb}$ administration is a vaccine-like response thus; we expected to observe a wave of PB peaking several days after IFX infusion. It was previously demonstrated that boost vaccines induce a strong proliferation of $\mathrm{PBs}$ and $\mathrm{mBCs}$ that can be detected in the blood circulation several days after the boost $(33,34)$. To test if IFX administration induces a vaccine like response, we collected blood samples from a patient that was found to be positive to ADA at two time points: prior to IFX infusion (D0) and 10 days after IFX infusion (D10). The second time point (D10) was determined in order to capture an enriched population of antigen-specific $\mathrm{PB}$ as well as $\mathrm{mBC}$ that enable the establishment of a donor-specific $\mathrm{V}_{\mathrm{H}}$ database for the proteomic interpretation of peptides derived from ADA.

Peripheral blood mononuclear cells (PBMCs) were sorted by FACS and the frequency of $\mathrm{PB}$ $\left(\mathrm{CD}^{-} \mathrm{CD} 19^{+} \mathrm{CD} 20^{-} \mathrm{CD} 27^{++} \mathrm{CD} 38^{++}\right)$and $\mathrm{mBC}$ $\left(\mathrm{CD}^{-} \mathrm{CD} 19^{+} \mathrm{CD} 20^{+} \mathrm{CD} 27^{+}\right)$subsets were determined. 
A

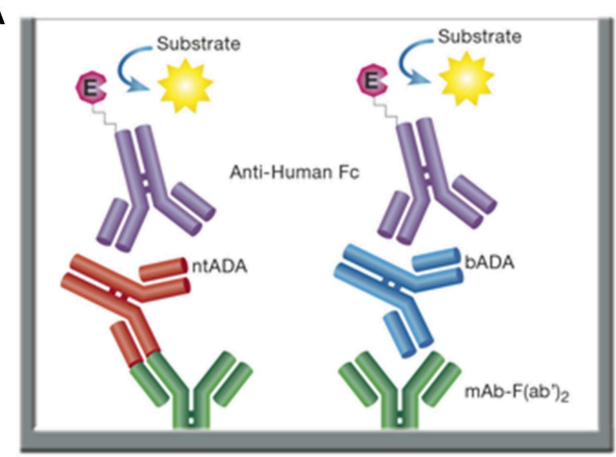

B

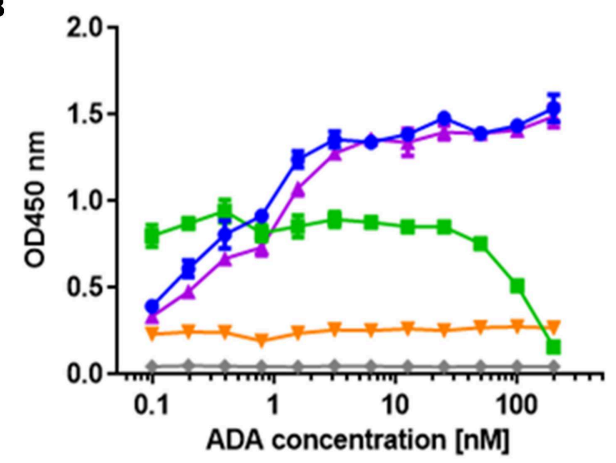

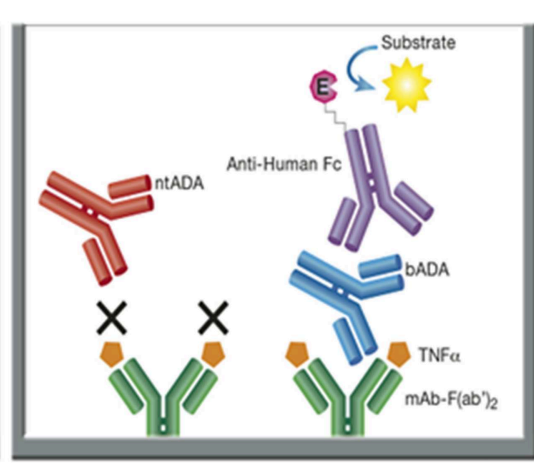

$\rightarrow \mathrm{ADA}+$ rhTNF $\alpha$ anti Fc-HRP

$\rightarrow$ - ADA + rhTNF $\alpha$ anti HisTag-HRP

$\star$ ADA - anti FC-HRP

$\rightarrow$ Control - anti FC-HRP

$\rightarrow$ Control - anti HisTag-HRP

FIGURE 4 | Configuration of the assay for determining the neutralization index of ADA in patient sera and competitive ELISA between ADA and rhTNF $\alpha$. (A) The newly developed $m A b-F\left(a b b_{2}\right)_{2}$ based bio-immunoassay configuration (left) and the modified configuration where $m A b-F(a b ')_{2}$ binding site is blocked by saturating the assay with rhTNF $\alpha$ (right). (B) Competitive effect of rhTNF $\alpha$ on ADA binding to IFX-F(ab') $)_{2}$. ELISA plate was coated with $5 \mu \mathrm{g} / \mathrm{ml}$ of IFX-F(ab') ${ }_{2}$. ADA standard was diluted 3 -fold in blocking solution supplemented with $5 \mathrm{nM}$ rhTNF $\alpha$. ADA diluted 3-fold in blocking solution without the presence of rhTNF $\alpha$ served as a control.

We identified a 13-fold increase in the frequency of $\mathrm{PB}$ at $\mathrm{D} 10$ and no increase in the $\mathrm{mBC}$ compartment. The $\mathrm{PB}$ data suggests that the B cell dynamics following IFX infusion exhibits vaccine-like characteristics in accordance with our working hypothesis (Table 2, Figure S3).

\section{Antibody Repertoire of ADA Encoding B-Cells}

The waves of $\mathrm{PB}$ following challenge is enriched with antigenspecific $B$ cells $(23,32,35)$. Based on this, a major fraction of $P B$ at $\mathrm{D} 10$ post-mAb infusion is expected to comprise $\mathrm{B}$ cell clones responding to the current antigen challenge. Thus, the repertoire of B cells at two time points (pre- and post-infusion) is predicted to represent the overall differences in the ongoing ADA encoding $\mathrm{B}$ cell response.

This diversity of antibodies is accomplished by several unique molecular mechanisms, including chromosomal V(D)J rearrangement, somatic hypermutations (SHM) and class switch recombination (25), processes that are mediated by recombination-activating gene (RAG) and activation-induced cytidine deaminase (AID), respectively. The AID enzyme functions mainly in secondary lymph nodes named germinal centers. Next-generation sequencing (NGS) of the antibody variable regions ( $\mathrm{V}$-genes) coupled with advanced bioinformatics tools provides the means to elucidate the antigen-specific antibody repertoire's immense diversity (36). To deep sequences antibodies' V-genes, recovered RNA from sorted $\mathrm{PB}$ and $\mathrm{mBC}$ was used as the template for first-strand cDNA synthesis, followed by PCR amplification steps to produce barcoded amplicons of the $\mathrm{V}$-genes of the antibody heavy chains $\left(\mathrm{V}_{\mathrm{H}}\right)$ as described previously (24). While NGS of antibodies is a powerful tool for immune repertoire analysis, relatively high rates of errors accumulate during the experimental procedure. To overcome this challenge, we generated duplicates of the antibody $\mathrm{V}$-gene amplicons and sequenced them using the Illumina MiSeq platform $(2 \times 300 \mathrm{bp})$. The resultant $\mathrm{V}_{\mathrm{H}}$ sequences were processed using our recently reported ASAP webserver that was specifically developed to analyze NGS of antibody V-gene sequences derived from replicates (25).

In our analysis, we concentrated on several repertoire measures that collectively provide a molecular level characterization of the ADA: (i) $\mathrm{V}(\mathrm{D}) \mathrm{J}$ family usage; (ii) CDR3 length distribution; (iii) SHM levels, and, (iv) isotype distribution. Our data revealed several interesting antibody repertoire features that may shed light on the molecular mechanism involved in the formation of ADA.

\section{V(D)J Gene Family Usage Is Stable}

Examining the V(D)J family usage is important to determine whether the basal gene frequency is similar to the expected 


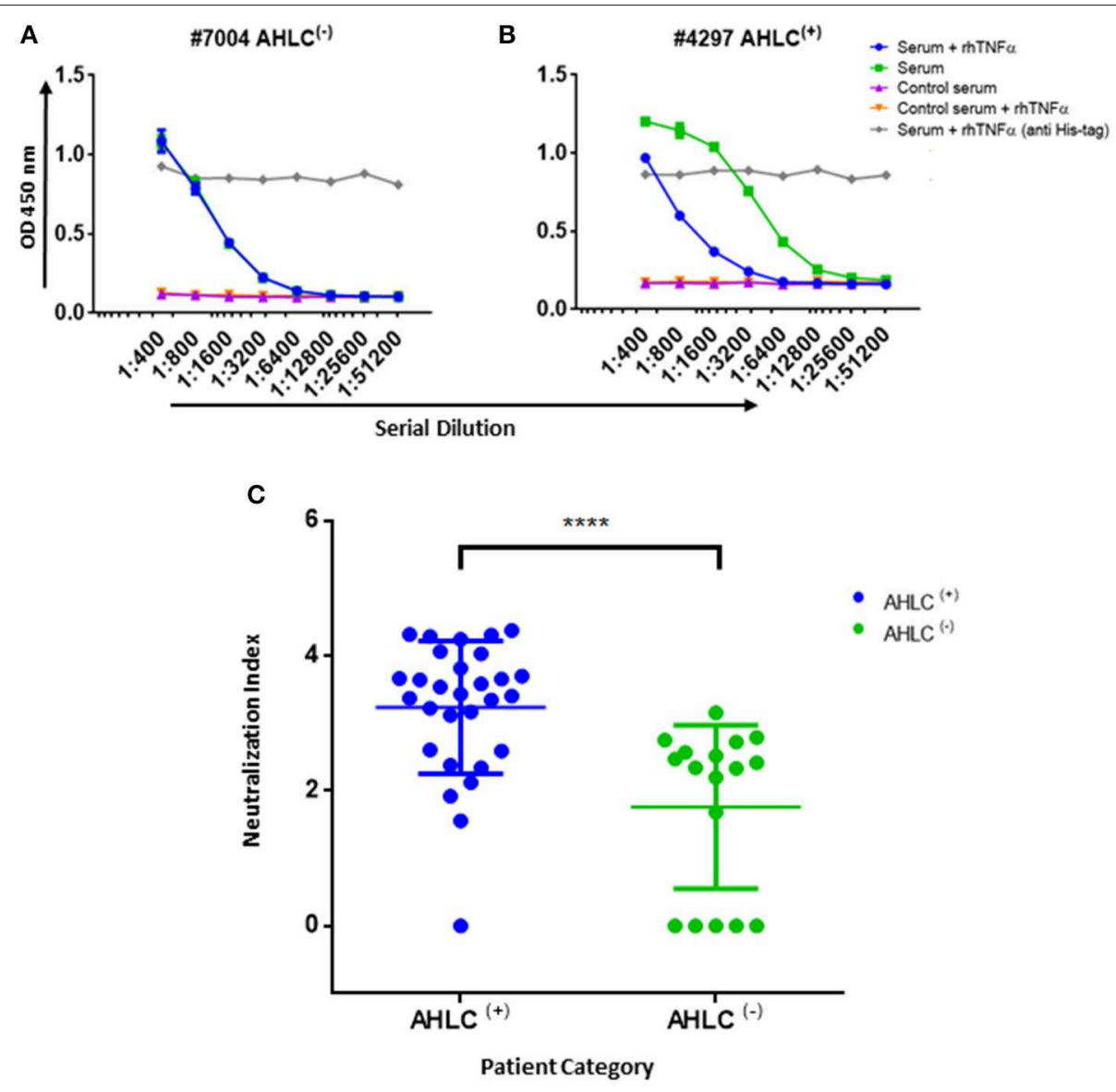

FIGURE 5 | Neutralization index ELISA. (A) Graph representing the ELISA results obtained utilizing the neutralization assay on serum that was designated as AHLC ${ }^{(-)}$ and $\mathbf{( B )} A H L C^{(+)}$. In both $(\mathbf{A}, \mathbf{B})$ the effect of soluble TNF $\alpha$ on ADA detection was evaluated and neutralization index was determined. (C) Scatter plot consolidating the

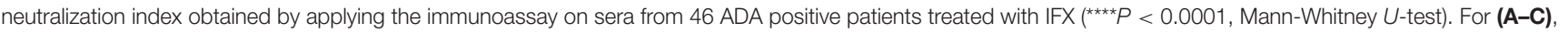
averages were calculated as mean, with error bars indicating s.d.

TABLE 2 | B cell frequency of a patient treated with IFX.

\begin{tabular}{|c|c|c|c|c|c|c|c|c|}
\hline \multirow[t]{2}{*}{ Time point } & \multirow[t]{2}{*}{$\begin{array}{l}\text { B cell } \\
\text { subset }\end{array}$} & \multirow{2}{*}{$\begin{array}{c}\% \text { Frequency of sorted } \\
\text { cells (out of CD19+ } \\
\text { cells) }(\%)\end{array}$} & \multicolumn{2}{|c|}{$\begin{array}{l}\text { No. of raw paired-end } \\
\text { sequencing reads }\end{array}$} & \multicolumn{3}{|c|}{$\begin{array}{l}\text { No. of filtered paired-end sequencing } \\
\text { read }\end{array}$} & \multirow{2}{*}{$\begin{array}{l}\text { No. of unique IGH } \\
\text { clonotypes extracted } \\
\text { (Unique CDRH3) }\end{array}$} \\
\hline & & & Replicate A & Replicate B & Replicate A & Replicate B & Joint & \\
\hline \multirow[t]{2}{*}{ DO } & PB & 0.9 & 39,129 & 63,168 & 12,863 & 19,082 & 2,041 & 1,294 \\
\hline & $\mathrm{mBC}$ & 10 & 714,722 & 639,984 & 121,998 & 111,373 & 30,725 & 9,146 \\
\hline D10 & PB & 11.5 & 167,859 & 151,849 & 49,762 & 46,192 & 10,341 & 5,590 \\
\hline
\end{tabular}

frequency and if the B cell response following IFX infusion drives $\mathrm{B}$ cells to exhibit a preferential $\mathrm{V}(\mathrm{D}) \mathrm{J}$ gene usage. Therefore, we examined the frequency of family usage at two time points (D0 and D10), within PB and $\mathrm{mBC}$ subsets across isotypes (IgG and $\operatorname{IgM}$ ). The $\mathrm{V}(\mathrm{D}) \mathrm{J}$ family usage showed no marked difference between the two time points, B cell subsets and isotypes. The frequency of $\mathrm{V}$-gene family usage was also found to have similar frequency profile as previously described $(37,38)$. For example, the V-gene family frequency showed that the V3, V4, and V1 have the most prevalent representation followed by V2, V5, and V6 that had significantly lower frequencies (Figure 6). The same pattern trends were identified for the $\mathrm{D}$ and J family usage.

\section{CDRH3 Length Increases Following IFX Infusion}

Composed of the $\mathrm{V}(\mathrm{D}) \mathrm{J}$ join with its inherent junctional diversity, the CDRH3 specifies the antibody $\mathrm{V}_{\mathrm{H}}$ clonotype. The $\mathrm{V}_{\mathrm{H}}$ clonotype is an important immunological concept because 


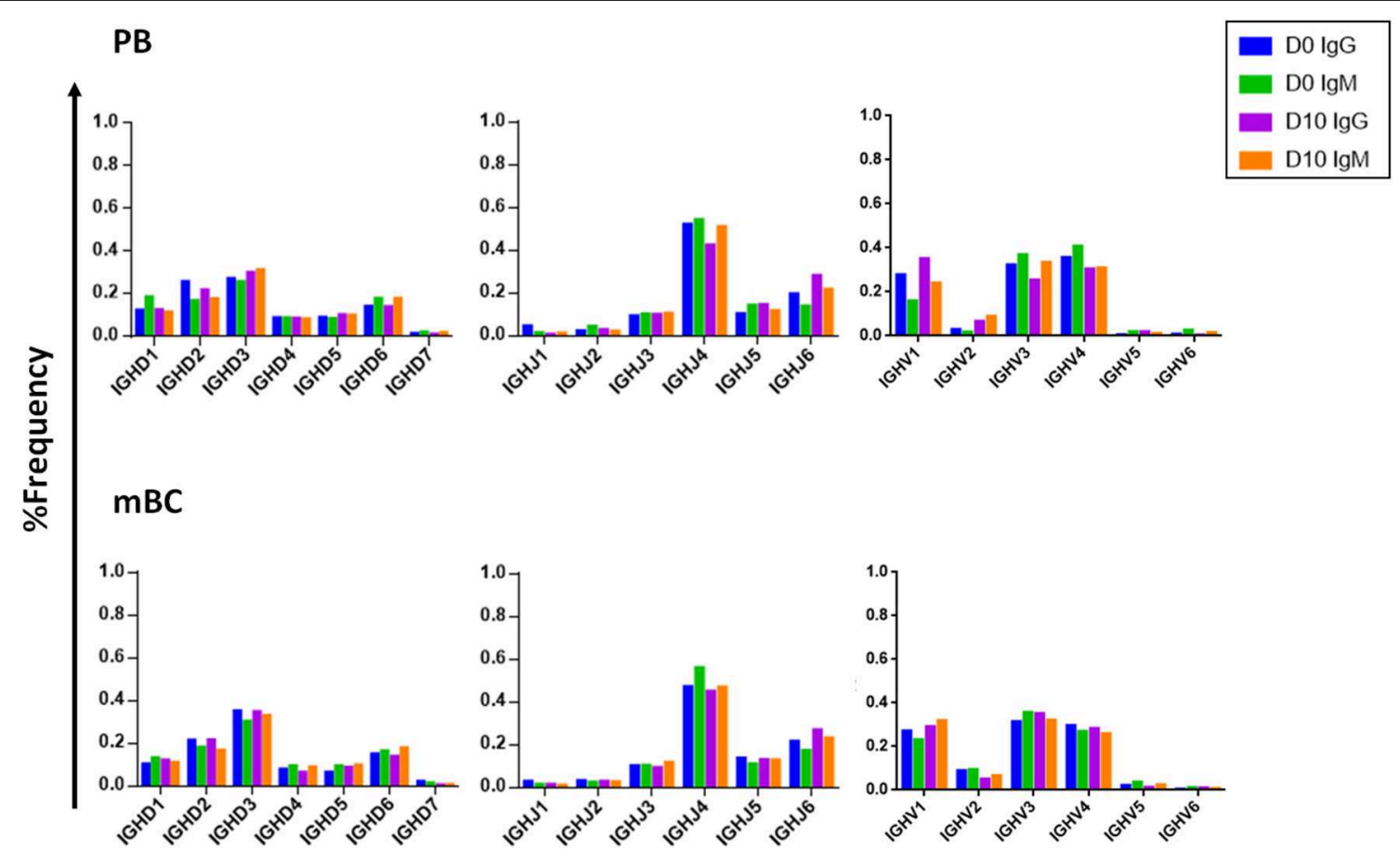

FIGURE 6 | V, D, and J family usage in B cell following IFX infusion. mBC and PB from a patient treated with IFX were collected at two time points (D0, D10) and processed for NGS analysis. The $\mathrm{V}$ family usage showed no difference between D0 and D10, different B cell subsets and isotypes. The D and $\mathrm{J}$ family usage showed no difference between time points.

it accounts for antibodies that likely originate from a single Bcell lineage and may provide insight on the evolution of the antigen-specific response (39). Here we defined $V_{H}$ clonotype as the group of $\mathrm{V}_{\mathrm{H}}$ sequences that share germ-line $\mathrm{V}$ and $\mathrm{J}$ segments and have identical CDRH3 sequences. By examining the length distribution of $\mathrm{CDRH} 3$ from $\mathrm{PB}$ across isotypes and time point we observed a shift toward longer CDRH3 at D10 (Figure 7). Interestingly, this observation is in contrast to previous studies that reported a decrease in the CDRH3 length post-immunization with pneumococcal (40) and hepatitis $B$ vaccines (41) and when comparing antigen experienced B cell to naïve B cells (42).

\section{Somatic Hypermutation Levels Decreases Following IFX Infusion}

Examining the level of SHM following vaccination provides insights regarding the extent of the affinity maturation that antigen-stimulated B cell undergo. It was previously reported that boost vaccination induces a substantial increase of the SHM levels when comparing post- to pre-vaccination (41). Despite the vaccine like response following IFX infusion, we observed in the PB compartment a significant decrease in the SHM levels post-infusion, regardless if the mutations were synonymous and non-synonymous (Figure 8).

\section{Proteomic Analysis of ADA}

Analysis of serum antibodies provides a comprehensive profile of the humoral immune response and is complementary to the transcriptomic analysis derived from NGS of the antibody $\mathrm{V}_{\mathrm{H}}$. Applying an approach that integrates NGS and tandem mass spectrometry (LC-MS/MS) has been shown to provide valuable data regarding the composition of antigen-specific serum antibodies and their relationship to B cells and generates new insights regarding the development of the humoral immune response in disease and following vaccination $(23,32)$. Here we utilized the previously developed omics approach $(26,39)$ to elucidate the serum ADA composition following IFX infusion. ADA from $10 \mathrm{ml}$ of serum collected at D0 and D10 were subjected to protein $G$ affinity chromatography and total of $9 \mathrm{mg}$ of recovered IgG was digested by IdeS to remove the $\mathrm{Fc}$ regions that may mask the MS/MS signal obtained from low abundant peptides. Following $5 \mathrm{~h}$ of digestion, the reaction mixture was subjected to custom made affinity column where the IFX-F(ab') $)_{2}$ was coupled to agarose beads and served as the antigen to isolate ADA. Recovered $48.57 \mu \mathrm{g}$ polyclonal $\mathrm{ADA}-\mathrm{F}\left(\mathrm{ab}^{\prime}\right)_{2}$ [i.e., IFX-F( $\left(\mathrm{ab}^{\prime}\right)_{2}$-specific $\mathrm{F}\left(\mathrm{ab}^{\prime}\right)_{2}$ ] in the elution fraction and total $\mathrm{F}\left(\mathrm{ab}^{\prime}\right)_{2}$ [depleted from $\mathrm{ADA}-\mathrm{F}(\mathrm{ab})_{2}$ ] in the flow through fraction were digested with trypsin and injected to highresolution tandem mass spectrometer analyzer in triplicates. LCMS/MS raw data files were analyzed using MaxQuant using label free quantitation mode (LFQ) and searched against the custom antibody V-gene database derived from the NGS data of B cells isolated from the same donor. Identified peptide from the interpretation of the proteomic spectra were stratified into three types of peptides: informative peptides (iPeptide) that map uniquely to one antibody clonotype in a region that is upstream 


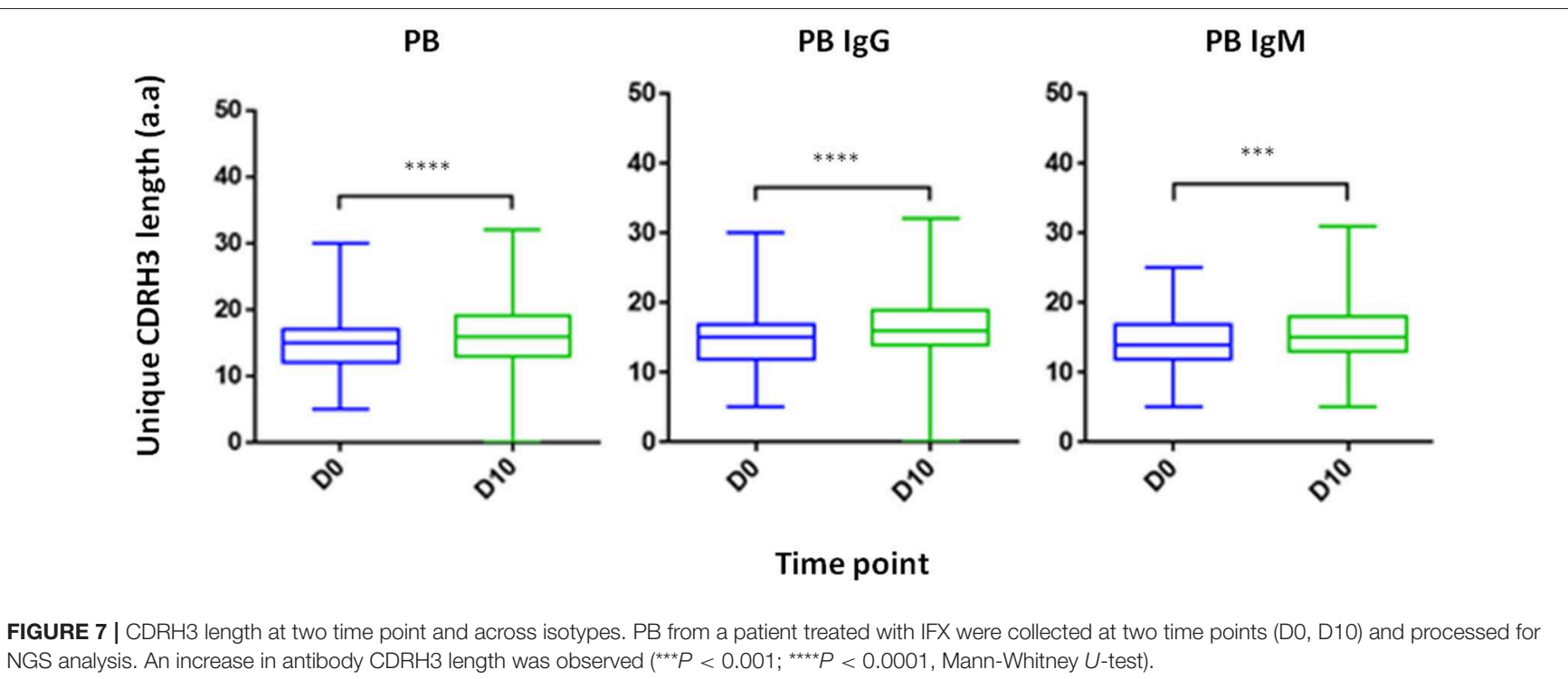

NGS analysis. An increase in antibody CDRH3 length was observed $\left({ }^{\star \star \star} P<0.001 ;{ }^{\star \star * \star} P<0.0001\right.$, Mann-Whitney $U$-test).
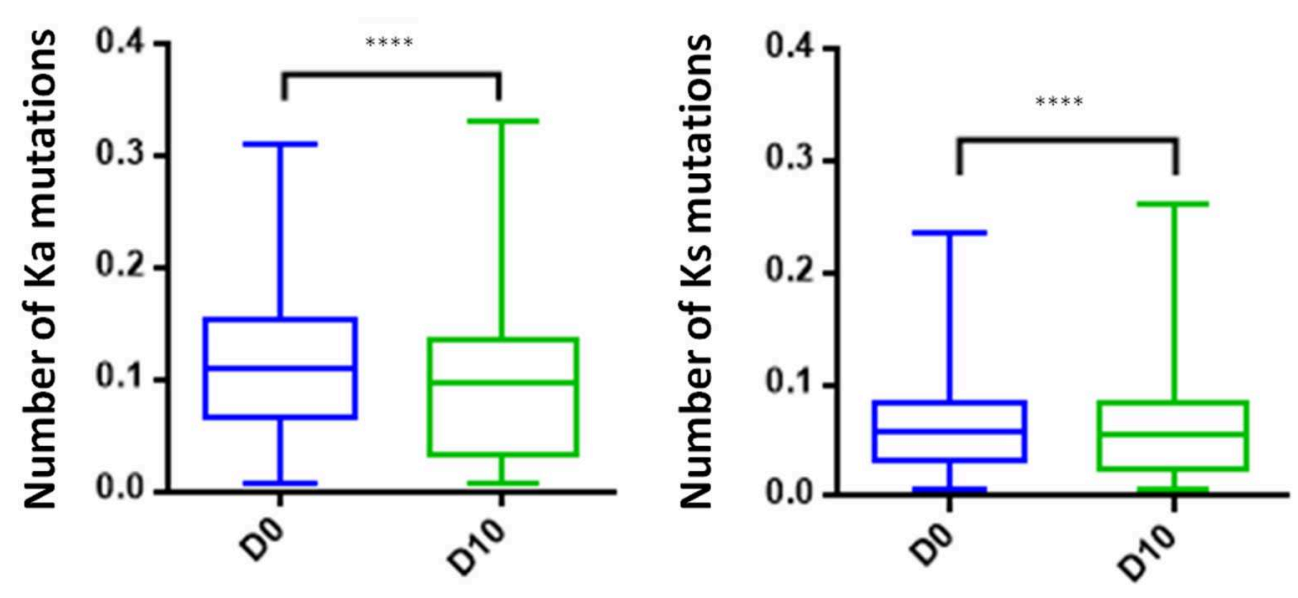

\section{Time point}

FIGURE 8 | Somatic hyper mutations. PB from a patient treated with IFX were collected at two time points (D0, D10) and processed for NGS analysis. A decrease in the number of Ka mutations (number of non-synonymous mutation per codon) and Ks mutations (number of synonymous mutations per codon) was observed at D10 ${ }^{\star \star \star \star \star} P<0.0001$, Mann-Whitney $U$-test).

to the CDRH3, non-informative CDRH3 peptides (niCDRH3) that map to the $\mathrm{CDRH} 3$ region of the antibody but do not map uniquely to a single antibody clonotype and informative CDRH3 peptides (iCDRH3) that map uniquely to a single antibody clonotype. Summary of identified peptides in LC-MS/MS are shown in Table 3 . Beyond the designation as $i \mathrm{CDRH} 3$ peptides, additional filtration steps were applied including peptides that were present in more than 2 replicates, peptides in elution that show $5 \times$ fold frequency than in the flow through. The $i \mathrm{CDRH} 3$ peptides enabled the identification of 62 unique ADA CDRH3 clonotypes with 205 associated full-length V-gene sequences. The resulting $\mathrm{V}$-gene sequences were analyzed to determine their $\mathrm{V}(\mathrm{D}) \mathrm{J}$ family usage and the B cell subset they are mapped to, based on our NGS data (Figure 9).
The $\mathrm{V}(\mathrm{D}) \mathrm{J}$ family usage of the antibody variable region sequences that were identified by LC-MS/MS (Figure 9A) showed a similar distribution as observed in the NGS data (Figure 6). V family frequency analysis showed that the V1, V3, and V4 are the most dominant $\mathrm{V}$ families followed by V2 and V5 that had significantly lower frequencies. D family frequency analysis showed that the D6, D3, D2, and D1 have the most prevalent representation, and $\mathrm{J}$ family frequency showed that the $\mathrm{J} 4, \mathrm{~J} 5$, and $\mathrm{J} 6$ have the most prevalent representation.

Next, we examined the distribution of the proteomically identified V-gene sequences to B cell subsets (Figure 9B) and found that the $\mathrm{V}$-genes predominantly map to $\mathrm{mBC}$ from D0 (46.83\%), followed by mBC from D10 (27.8\%). Moreover, we found that $23.9 \%$ of $\mathrm{V}$-genes map to D10 PB. Based on 
the dynamics of antibodies in serum (32), the majority of antibodies produced following a boost challenge are the product of pre-existing $\mathrm{mBC}$ cells that were re-activated following drug infusion, much like a response to a vaccine boost (23).

As mentioned above, flow cytometry of B cells following IFX administration allowed us to identify a substantial increase in the frequency of $\mathrm{PB}$ at D10, which suggests that the $B$ cell dynamics following IFX infusion exhibits vaccine-like characteristics. Therefore, we expected to find a majority of $\mathrm{V}$-gene sequences mapping to $\mathrm{IgG}^{+} \mathrm{B}$ cells that underwent class switch recombination in the germinal center. Surprisingly,

TABLE 3 | Summary of identified peptides and the corresponding clonotype and antibody somatic variences in the LC-MS/MS spectra.

\begin{tabular}{lcc}
\hline & Day 0 & Day 10 \\
\hline Total peptides & 908 & 3,177 \\
Total antibody peptides & 761 & 2,805 \\
Total CDRH3 & 42 & 224 \\
Present in $\geq 2$ technical replicates & 30 & 166 \\
Frequency ratio E/FT $>5$ & 11 & 81 \\
No of clones & 5 & 62 \\
No of somatic variances & 35 & 205 \\
\hline
\end{tabular}

E, elution; FT, flow-through. the majority of proteomically identified serum antibodies were mapped to $\operatorname{IgM}^{+}$B cells (Figure 9C).

Next, we aimed to provide support to the observation that $n t$ ADA preferably use the $\lambda$ light chain. By quantifying the accumulative intensities of peptides derived from the constant region of both $\kappa$ and $\lambda$ light chains, we calculated the ratio of $\kappa: \lambda$ light chain in the elution fraction which comprise both the $n t \mathrm{ADA}$ and $b \mathrm{ADA}$ (ADA-IgG), and in the flow through fraction that represent ADA-depleted IgG (dep-IgG). The expected $\kappa / \lambda$ ratio of $\operatorname{IgG}$ in human serum is $2(66 \% \kappa$ and $33 \% \lambda)$. Indeed, proteomic analysis of the dep-IgG (D0 and D10), resulted in an average $\kappa / \lambda$ ratio of 2.1 . The same analysis of the ADAIgG showed a significant shift of the $\kappa / \lambda$ ratio to 1.19 . The proteomic analysis was carried out on samples from patient that exhibited a high neutralization index (have high levels of $n t$ ADA) and designated $\mathrm{ADA}^{+}$using AHLC (detects only ADA with $\lambda$ light chain). Brought together, this further suggests that $n t \mathrm{ADA}$ contribute to shift in the $\kappa: \lambda$ light chain ratio.

\section{DISCUSSION}

The use of therapeutic mAbs in treating a wide range of diseases and disorders is growing exponentially. Nonetheless, a major shortcoming of their use is the development of ADA in patients receiving the $\mathrm{mAb}$. Advances in $\mathrm{mAb}$ engineering have enabled the development of fully human mAbs with
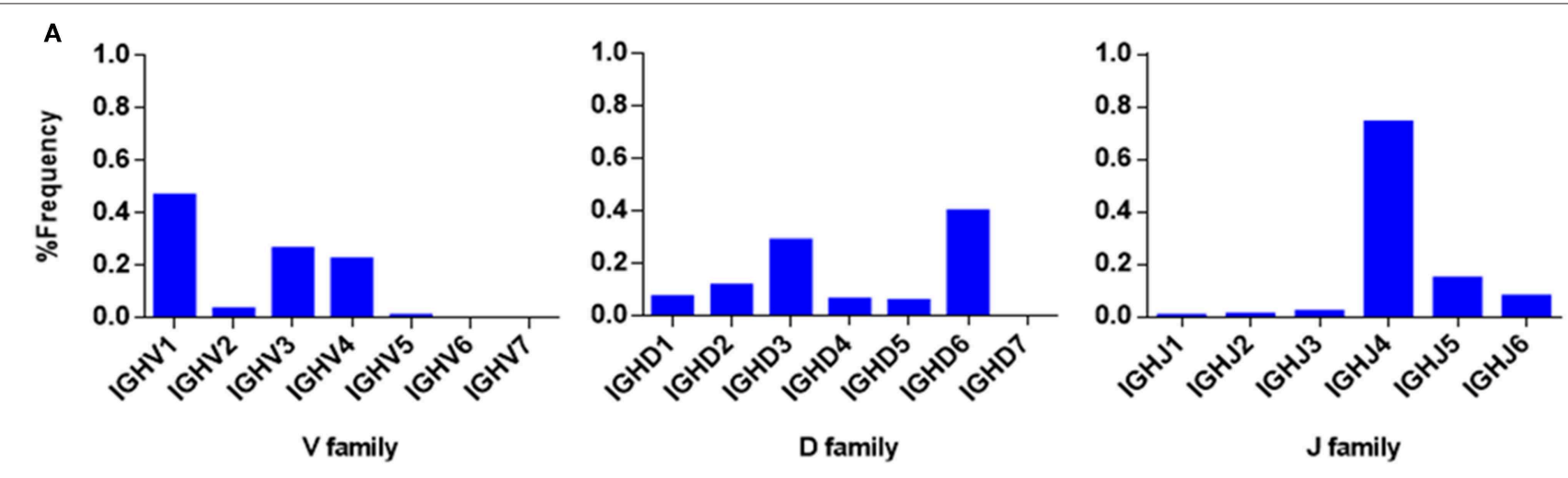

B

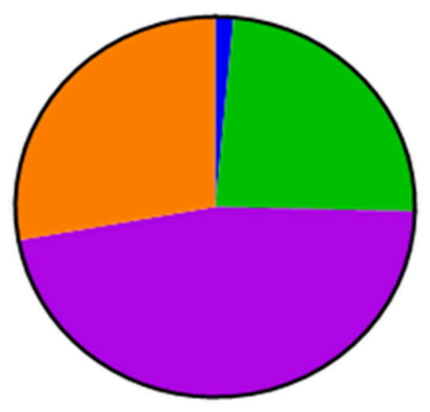

C

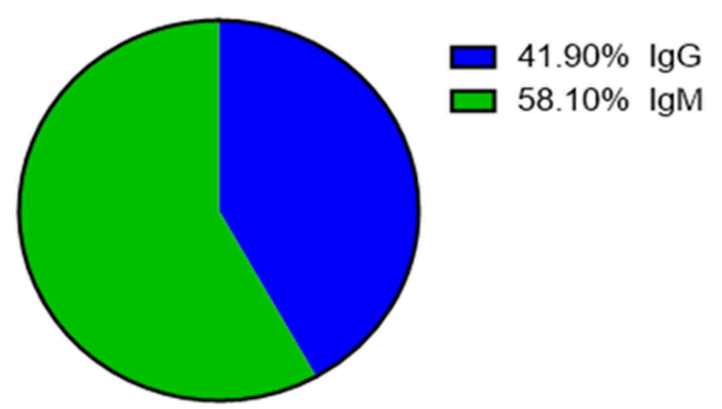

FIGURE 9 | V-gene and circulating antibody repertoire characteristics. (A) The V(D)J family usage of V-gene sequences that were identified by LC-MS/MS. (B) Mapping of V-gene sequences to B cell subsets and (C) isotypes, based on NGS data. 
reduced immunogenicity without abolishing it completely. Thus, a mAb administered to a patient can still induce an immune sensitization as reflected by the production of ADA, which is associated with low trough drug levels and can mediate loss of clinical response to the drug (20).

The precise mechanism underlying ADA production is unknown, and many questions related to its development remain unaddressed, including determining precise concentrations of ADA in serum, which portion of the ADA exhibits neutralizing capacity, the immune pathway governing the production of $\mathrm{ADA}$, and ultimately, the molecular composition of ADA at the sequence level. To address these questions, we chose the chimeric TNF $\alpha$ antagonist IFX as the model system. First, we aimed to quantify the ADA level in patient sera. Many methods were previously reported to evaluate serum ADA levels. These assays include radio-immunoassays (43), Biotin-drug Extraction with Acid Dissociation (BEAD) (44), Precipitation and acid dissociation (PANDA) (45), affinity capture elution ELISA (ACE) (46), and Homogenous Mobility Shift Assay (HMSA) (47). While these assays are not limited to the $\lambda$ light chain detection like the AHLC assay, they provide mostly qualitative measures to assist physicians in deciding the most appropriate intervention when treating patients, and many (if not all) studies underestimated actual ADA levels (19). These assays also lack a standardization methodology that can enable the comparison of ADA levels across health centers.

To provide quantitative measures describing the molecular landscape of $\mathrm{ADA}$, we first developed a bio-immunoassay that would allow quantify ADA levels based on the $\mathrm{F}\left(\mathrm{ab}^{\prime}\right)_{2}$ region of the $\mathrm{mAb}$ because previous reports indicated that the $\mathrm{ADA}$ generated from $\mathrm{mAb}$ administration are mostly anti-idiotypic (21). Indeed, the bio-immunoassay demonstrated higher sensitivity compared with the AHLC assay used initially to detect ADA and was able to detect ADA when the AHLC assay could not. Leveraging its improved sensitivity compared to the AHLC assay, we applied our proprietary assay on sera from 54 patients treated with IFX and found that patients designated as $\mathrm{AHLC}^{(+)}$showed significantly higher levels of ADA (mean: $264 \mu \mathrm{g} / \mathrm{ml}$ ) compared to the AHLC $^{(-)}$group (mean: $59.64 \mu \mathrm{g} / \mathrm{ml}$ ). These results support the clinical use of AHLC assay because overall, patients were correctly stratified leading to clinical decision-making that was based on a valid indicative assay. Notwithstanding, the applicability of the AHLC assay, the newly developed $\mathrm{F}\left(\mathrm{ab}^{\prime}\right)_{2}$-based bio-immunoassay demonstrated that ADA levels can reach extreme concentrations that were not detected using the AHLC assay.

Some patients who develop ADA in response to IFX present a prolonged remission with maintenance therapy despite repeated indications of high ADA and low IFX trough levels (20). The mechanism of action of these ADA has significant influence on drug efficacy. For example, $b \mathrm{ADA}$ are most likely to enhance the clearance of a drug whereas ntADA will prevent a drug from binding to its target. Hence, it is important to differentiate between $b \mathrm{ADA}$ and $n t \mathrm{ADA}$, or in other words, a need exists to identify sera with high levels of $n t \mathrm{ADA}$ that may predict the likelihood of a patient losing a favorable response to an administrated $\mathrm{mAb}$. To achieve this, we further revised our bio-immunoassay to qualitatively measure the neutralization index of ADA in the serum of patients treated with IFX. Of note, as the neutralization index is a qualitative and not a quantitative index, some patients may exhibit relatively low ADA levels and high neutralization index. Using this assay on sera from the $46 \mathrm{ADA}$ positive patients, revealed that patients who tested positive utilizing the AHLC assay, exhibit a significantly higher neutralization index than patients tested negatively for it [i.e., AHLC ${ }^{(-)}$]. Noteworthy, the AHLC assay is based on the anti- $\lambda$ light chain antibody at the detection stage, suggesting that sera with high neutralization index comprise ADA that preferably use the $\lambda$ light chain (either $b$ ADA or $n t \mathrm{ADA})$. This phenomenon received additional support from our proteomic analysis in which we compared the changes in the ratio between peptides derived from $\kappa$ and $\lambda$ constant light chains from ADA-IgG pool and peptide derived from depleted ADA IgG polyclonal pool (dep-IgG). This analysis demonstrated that the $\kappa / \lambda$ ratio in the total IgG compartment is as expected and is decreased in the mAb-specific compartment $(\kappa / \lambda$ ratio 2.1 and 1.19 for dep-IgG and ADA-IgG, respectively). The preferential use of the $\lambda$ light chain in neutralizing antibodies has been previously reported $(21,48)$, however, the authors of those studies did not provide an explanation beyond the structural adaptability of the light chain toward the target. The relevance of the reported cases showing $\lambda$ chain bias is not clear. Similar phenomena was reported in B-1 subpopulation, unlike follicular B cells, B-1 cells exhibit an increased frequency of lambda light chains (49). The recurrence of BCRs with the enrichment of $\lambda$ light chain has been considered to result from strong antigen-dependent selection of the B-1 cell repertoire (50).

Repetitive administration of mAbs may induce a strong humoral response manifested in the production of ADA. We hypothesized that $\mathrm{mAb}$ administration is similar to the response that occurs following a boost vaccine. Others and we have demonstrated that boost vaccines induce a strong proliferation of $\mathrm{PB}$ that can be detected in blood circulation several days after the boost. The "wave" of B cells after the boost vaccine are dominated by antigen-specific B cell (34) thus, repertoire analysis of these cells can provide invaluable data about the antigenspecific antibody repertoires. Utilizing flow cytometry showed an order of magnitude increase in PB compartment 10 days after IFX infusion, suggesting that the immune response following IFX administration is indeed similar to a vaccine response. To the best of our knowledge, this is the first report to identify a vaccine like response following therapeutic $\mathrm{mAb}$ administration.

Next, we aimed to provide a comprehensive repertoire profile of the $\mathrm{B}$ cells induced after $\mathrm{mAb}$ administration. To achieve this, we applied an "omics" approach as previously described $(23,26,39)$ that is based on the integration of NGS of the V-genes and proteomic analysis of serum ADA. NGS of $\mathrm{V}$-genes revealed no bias in the $\mathrm{V}(\mathrm{D}) \mathrm{J}$ usage across isotypes, cell types, and time point. These data suggest that the original repertoire that existed before $\mathrm{mAb}$ administration and antigen-specific repertoire induced by IFX administration is formed by random recombination processes without preferential use of any particular $\mathrm{V}(\mathrm{D}) \mathrm{J}$ 
segment. Comparative repertoire analysis of the V-genes between time points (before and after IFX administration) revealed that post-IFX administration, $\mathrm{PB}$ exhibit longer CDRH3 and lower SHM rates. Although the B cell dynamics after $\mathrm{mAb}$ administration are similar to those that occur after a boost vaccine, the repertoire measures show a different profile. It was previously reported that the antibodies generated after a boost vaccine exhibit shorter CDRH3, high SHM (40-42).

To explain these data we revisited two reports: the first describes how the immune response in $\mathrm{TNF} \alpha$-deficient mice was "diverted" to the marginal zone instead of to the germinal center (51) and the characteristics of the immune response in the marginal zone is directly affected by low levels of the AID that in turn is reflected in lower SHM rate. The second reported a skewed $\lambda$ chain usage in B-1 cells (49). Based on these reports we propose a mechanistic model according to which administration of $\mathrm{TNF} \alpha$ antagonist blocks the $\mathrm{TNF} \alpha$ on one hand and induces a vaccine-like response on the other. Due to the $\mathrm{TNF} \alpha$ blockade, immune response of $\mathrm{B}$ cells occurs extra follicular where AID is downregulated, thus the encoded ADA exhibit lower SHM rates. Moreover, the data suggests that the immune response following $\mathrm{mAb}$ administration may be a $\mathrm{T}$ cell independent (TI) response which is governed by the B-1 cell linage with the characteristics mentioned of an increased usage of $\lambda$ light chains and little to non-evidence for SHM $(49,52)$.

Another possible mechanism that should be further explored is the strong TI immune response in the marginal zone that is also induced by a drug/ADA immune-complex (IC). It was previously suggested that many of the immune-mediated adverse effects attributed to ADA require the formation of an IC intermediate that can have a variety of downstream effects $(6,53)$. In the context of the system we investigated, administration of a TNF $\alpha$ antagonist will divert the immune response extra follicular either by TNF $\alpha$ blockade or by the formation of an IC carrying multiple $m A b s$ that can induce the cross-linking of cognate BCR. The BCR of ADA-encoding $\mathrm{B}$ cells will undergo co-clustering leading to their activation in the TI pathway.

Of note, insights from this study are restricted to the immune response following treatment with TNF $\alpha$ antagonists, as it is specifically affected by the drug's mechanism of action. First, $\mathrm{TNF} \alpha$ is a trimer that has the propensity to form immunocomplexes with the drug. Second, blocking TNF $\alpha$ "simulates" a scenario that was observed in TNF $\alpha$ knockout mice. Combined, these attributes contribute to the specific nature of the immune response which is suggested to be diverted to the extra follicular, TI immune response. Moreover, the deep analysis data was obtained from one patient. However, this patient exhibited a set of attributes including high ADA level, high neutralization index, low trough level, and lack of immunosuppressant treatments. These attributes enabled to generate insights that are directly relevant to the drug administration.

In our study we examined molecular aspects related to the formation of ADA. To the best of our knowledge, this is the first report describing ADA repertoire that resulted in insights about a possible mechanism of ADA formation. Further work will be needed to elucidate additional phenotypic markers of the $\mathrm{B}$ cells induced by $\mathrm{mAb}$ administration and the role of IC in the activation of the $\mathrm{B}$ cell. Moreover, the mechanism described here covers the response to a TNF $\alpha$-antagonist, and by using the same omics approaches, it will be highly informative to study the B cell response following treatment with other mAbs that induce ADA formation. We envision that high throughput data obtained from such studies can facilitate our understanding on why and how, mAb administration generates ADA and eventually may contribute guidelines for engineering therapeutic mAbs with reduced immunogenicity.

\section{DATA AVAILABILITY STATEMENT}

The raw data supporting the conclusions of this article will be made available by the authors, without undue reservation, to any qualified researcher.

\section{ETHICS STATEMENT}

All subjects signed an informed consent, and the study was approved by the Ethics Committee of Sheba medical center.

\section{AUTHOR CONTRIBUTIONS}

SB-H, IB, and YW conceived the research. AV-M, SR, and YW designed the experiments. AV-M, SR, MY, EF, and YD performed the experiments. AV-M, SR, SB-H, MY, EF, BU, $\mathrm{UK}$, and OP collected and processed clinical samples. AV-M, $\mathrm{AK}$, and YW carried out data analysis. AV-M and YW wrote the manuscript.

\section{FUNDING}

This work was partially supported by BSF Grant No. 2017359 (YW).

\section{ACKNOWLEDGMENTS}

We are grateful to George Georgiou for assisting with the LC-MS/MS measurements at UT Austin, for Ulrich von Pawel-Rammingen from the Department of Molecular Biology, Umea University who kindly donated the plasmid with the gene encoding the IdeS. This manuscript has been released as a preprint at bioRxiv (54).

\section{SUPPLEMENTARY MATERIAL}

The Supplementary Material for this article can be found online at: https://www.frontiersin.org/articles/10.3389/fimmu. 2019.02921/full\#supplementary-material 


\section{REFERENCES}

1. Grilo AL, Mantalaris A. The increasingly human and profitable monoclonal antibody market. Trends Biotechnol. (2019) 37:9-16. doi: 10.1016/j.tibtech.2018.05.014

2. van Schouwenburg PA, Rispens T, Wolbink GJ. Immunogenicity of antiTNF biologic therapies for rheumatoid arthritis. Nat Rev Rheumatol. (2013) 9:164-72. doi: 10.1038/nrrheum.2013.4

3. De Groot AS, Scott DW. Immunogenicity of protein therapeutics. Trends Immunol. (2007) 28:482-90. doi: 10.1016/j.it.2007.07.011

4. Hansel TT, Kropshofer H, Singer T, Mitchell JA, George AJ. The safety and side effects of monoclonal antibodies. Nat Rev Drug Discov. (2010) 9:325-38. doi: $10.1038 / \mathrm{nrd} 3003$

5. Bloem K, Hernandez-Breijo B, Martinez-Feito A, Rispens T. Immunogenicity of therapeutic antibodies: monitoring antidrug antibodies in a clinical context. Ther Drug Monit. (2017) 39:327-32. doi: 10.1097/FTD.0000000000000404

6. Krishna M, Nadler SG. Immunogenicity to biotherapeutics-the role of anti-drug immune complexes. Front Immunol. (2016) 7:21. doi: 10.3389/fimmu.2016.00021

7. Nelson AL, Dhimolea E, Reichert JM. Development trends for human monoclonal antibody therapeutics. Nat Rev Drug Discov. (2010) 9:767-74. doi: $10.1038 / \mathrm{nrd} 3229$

8. Ben-Horin S, Heap GA, Ahmad T, Kim H, Kwon T, Chowers Y. The immunogenicity of biosimilar infliximab: can we extrapolate the data across indications? Expert Rev Gastroenterol Hepatol. (2015) 9(Suppl. 1):27-34. doi: 10.1586/17474124.2015.1091307

9. Bendtzen K. Immunogenicity of anti-TNF- $\alpha$ biotherapies: II. clinical relevance of methods used for anti-drug antibody detection. Front Immunol. (2015) 6:109. doi: 10.3389/fimmu.2015. 00109

10. Putnam WS, Prabhu S, Zheng Y, Subramanyam M, Wang Y-MC. Pharmacokinetic, pharmacodynamic and immunogenicity comparability assessment strategies for monoclonal antibodies. Trends Biotechnol. (2010) 28:509-16. doi: 10.1016/j.tibtech.2010.07.001

11. Sands BE, Anderson FH, Bernstein CN, Chey WY, Feagan BG, Fedorak RN, et al. IInfliximab maintenance therapy for fistulizing Crohn's disease. N Engl J Med. (2004) 350:876-85. doi: 10.1056/NEJMoa030815

12. Mitoma H, Horiuchi T, Hatta N, Tsukamoto H, Harashima S, Kikuchi Y, et al. Infliximab induces potent anti-inflammatory responses by outside-toinside signals through transmembrane TNF-alpha. Gastroenterology. (2005) 128:376-92. doi: 10.1053/j.gastro.2004.11.060

13. Ben-Horin S, Vande Casteele N, Schreiber S, Lakatos PL. Biosimilars in inflammatory bowel disease: facts and fears of extrapolation. Clin Gastroenterol Hepatol. (2016) 14:1685-96. doi: 10.1016/j.cgh.2016.05.023

14. Baker MP, Reynolds HM, Lumicisi B, Bryson CJ. Immunogenicity of protein therapeutics: the key causes, consequences and challenges. Self Nonself. (2010) 1:314-22. doi: 10.4161/self.1.4.13904

15. Ungar B, Engel T, Yablecovitch D, Lahat A, Lang A, Avidan B, et al. Prospective observational evaluation of time-dependency of adalimumab immunogenicity and drug concentrations: the poetic study. Am J Gastroenterol. (2018) 113:890-8. doi: 10.1038/s41395-018-0073-0

16. Ungar B, Chowers Y, Yavzori M, Picard O, Fudim E, Har-Noy O, et al. The temporal evolution of antidrug antibodies in patients with inflammatory bowel disease treated with infliximab. Gut. (2014) 63:1258-64. doi: 10.1136/gutjnl-2013-305259

17. Vincent FB, Morand EF, Murphy K, Mackay F, Mariette X, Marcelli C. Antidrug antibodies (ADAb) to tumour necrosis factor (TNF)specific neutralising agents in chronic inflammatory diseases: a real issue, a clinical perspective. Ann Rheum Dis. (2013) 72:165-78. doi: 10.1136/annrheumdis-2012-202545

18. Tatarewicz S, Miller JM, Swanson SJ, Moxness MS. Rheumatoid factor interference in immunogenicity assays for human monoclonal antibody therapeutics. J Immunol Methods. (2010) 357:10-6. doi: 10.1016/j.jim.2010.03.012

19. Bloem K, van Leeuwen A, Verbeek G, Nurmohamed MT, Wolbink GJ, van der Kleij D, et al. Systematic comparison of drug-tolerant assays for anti-drug antibodies in a cohort of adalimumab-treated rheumatoid arthritis patients. $J$ Immunol Methods. (2015) 418:29-38. doi: 10.1016/j.jim.2015.01.007
20. Ben-Horin S, Chowers Y. Tailoring anti-TNF therapy in IBD: drug levels and disease activity. Nat Rev Gastroenterol Hepatol. (2014) 11:243-55. doi: 10.1038/nrgastro.2013.253

21. Ben-Horin S, Yavzori M, Katz L, Kopylov U, Picard O, Fudim E, et al. The immunogenic part of infliximab is the $\mathrm{F}\left(\mathrm{ab}^{\prime}\right) 2$, but measuring antibodies to the intact infliximab molecule is more clinically useful. Gut. (2010) 60:41-8. doi: 10.1136/gut.2009.201533

22. Wenig K, Chatwell L, von Pawel-Rammingen U, Björck L, Huber R, Sondermann P. Structure of the streptococcal endopeptidase IdeS, a cysteine proteinase with strict specificity for IgG. Proc Natl Acad Sci USA. (2004) 101:17371-6. doi: 10.1073/pnas.0407965101

23. Lavinder JJ, Wine Y, Giesecke C, Ippolito GC, Horton AP, Lungu OI, et al. Identification and characterization of the constituent human serum antibodies elicited by vaccination. Proc Natl Acad Sci USA. (2014) 111:225964. doi: 10.1073/pnas.1317793111

24. Menzel U, Greiff V, Khan TA, Haessler U, Hellmann I, Friedensohn S, et al. Comprehensive evaluation and optimization of amplicon library preparation methods for high-throughput antibody sequencing. PLoS ONE. (2014) 9:e96727. doi: 10.1371/journal.pone.0096727

25. Avram O, Vaisman-Mentesh A, Yehezkel D, Ashkenazy H, Pupko T, Wine Y. ASAP, A webserver for immunoglobulin-sequencing analysis pipeline. Front Immunol. (2018) 9:1686. doi: 10.3389/fimmu.2018.01686

26. Boutz DR, Horton AP, Wine Y, Lavinder JJ, Georgiou G, Marcotte EM. Proteomic identification of monoclonal antibodies from serum. Anal Chem. (2014) 86:4758-66. doi: 10.1021/ac4037679

27. Cox J, Mann M. MaxQuant enables high peptide identification rates, individualized p.p.b.-range mass accuracies and proteome-wide protein quantification. Nat Biotechnol. (2008) 26:1367-72. doi: 10.1038/nbt.1511

28. Cox J, Hein MY, Luber CA, Paron I, Nagaraj N, Mann M. Accurate proteomewide label-free quantification by delayed normalization and maximal peptide ratio extraction, termed MaxLFQ. Mol Cell Proteom. (2014) 13:2513-26. doi: 10.1074/mcp.M113.031591

29. Cox J, Neuhauser N, Michalski A, Scheltema RA, Olsen JV, Mann M. Andromeda: a peptide search engine integrated into the MaxQuant environment. J Proteome Res. (2011) 10:1794-805. doi: 10.1021/pr101065j

30. von Pawel-Rammingen U, Johansson BP, Björck L. IdeS, a novel streptococcal cysteine proteinase with unique specificity for immunoglobulin G. EMBO J. (2002) 21:1607-15. doi: 10.1093/emboj/21.7.1607

31. Kopylov U, Mazor Y, Yavzori M, Fudim E, Katz L, Coscas D, et al. Clinical utility of antihuman lambda chain-based enzyme-linked immunosorbent assay (ELISA) versus double antigen ELISA for the detection of anti-infliximab antibodies. Inflam Bowel Dis. (2012) 18:1628-33. doi: 10.1002/ibd.21919

32. Lee J, Boutz DR, Chromikova V, Joyce MG, Vollmers C, Leung K, et al. Molecular-level analysis of the serum antibody repertoire in young adults before and after seasonal influenza vaccination. Nat Med. (2016) 22:1456-64. doi: $10.1038 / \mathrm{nm} .4224$

33. Haney DJ, Lock MD, Gurwith M, Simon JK, Ishioka G, Cohen MB, et al. Lipopolysaccharide-specific memory B cell responses to an attenuated live cholera vaccine are associated with protection against Vibrio cholerae infection. Vaccine. (2018) 36:2768-73. doi: 10.1016/j.vaccine.2018. 04.011

34. Davydov AN, Obraztsova AS, Lebedin MY, Turchaninova MA, Staroverov DB, Merzlyak EM, et al. Comparative analysis of B-cell receptor repertoires induced by live yellow fever vaccine in young and middle-age donors. Front Immunol. (2018) 9:2309. doi: 10.3389/fimmu.2018.02309

35. Blanchard-Rohner G, Pulickal AS, der Zijde CMJ-v, Snape MD, Pollard AJ. Appearance of peripheral blood plasma cells and memory B cells in a primary and secondary immune response in humans. Blood. (2009) 114:4998-5002. doi: 10.1182/blood-2009-03-211052

36. Greiff V, Menzel U, Haessler U, Cook SC, Friedensohn S, Khan TA, et al. Quantitative assessment of the robustness of next-generation sequencing of antibody variable gene repertoires from immunized mice. BMC Immunol. (2014) 15:40. doi: 10.1186/s12865-014-0040-5

37. Mroczek ES, Ippolito GC, Rogosch T, Hoi KH, Hwangpo TA, Brand MG, et al. Differences in the composition of the human antibody repertoire by B cell subsets in the blood. Front Immunol. (2014) 5:96. doi: 10.3389/fimmu.2014.00096 
38. Volpe JM, Kepler TB. Large-scale analysis of human heavy chain $\mathrm{V}(\mathrm{D}) \mathrm{J}$ recombination patterns. Immunome Res. (2008) 4:3. doi: 10.1186/1745-7580-4-3

39. Wine Y, Boutz DR, Lavinder JJ, Miklos AE, Hughes RA, Hoi KH, et al. Molecular deconvolution of the monoclonal antibodies that comprise the polyclonal serum response. Proc Natl Acad Sci USA. (2013) 110:2993-8. doi: 10.1073/pnas.1213737110

40. Ademokun A, Wu YC, Martin V, Mitra R, Sack U, Baxendale H, et al. Vaccination-induced changes in human B-cell repertoire and pneumococcal IgM and IgA antibody at different ages. Aging Cell. (2011) 10:922-30. doi: 10.1111/j.1474-9726.2011.00732.x

41. Galson JD, Trück J, Fowler A, Clutterbuck EA, Münz M, Cerundolo $\mathrm{V}$, et al. Analysis of $\mathrm{B}$ cell repertoire dynamics following hepatitis $B$ vaccination in humans, and enrichment of vaccine-specific antibody sequences. EBioMedicine. (2015) 2:2070-9. doi: 10.1016/j.ebiom.2015.11.034

42. DeKosky BJ, Lungu OI, Park D, Johnson EL, Charab W, Chrysostomou C, et al. Large-scale sequence and structural comparisons of human naive and antigen-experienced antibody repertoires. Proc Natl Acad Sci USA. (2016) 113:E2636-45. doi: 10.1073/pnas.1525510113

43. Svenson M, Geborek P, Saxne T, Bendtzen K. Monitoring patients treated with anti-TNF- $\alpha$ biopharmaceuticals: assessing serum infliximab and anti-infliximab antibodies. Rheumatology. (2007) 46:1828-34. doi: 10.1093/rheumatology/kem261

44. Lofgren JA, Wala I, Koren E, Swanson SJ, Jing S. Detection of neutralizing anti-therapeutic protein antibodies in serum or plasma samples containing high levels of the therapeutic protein. J Immunol Methods. (2006) 20:101-8. doi: $10.1016 /$ j.jim.2005.10.007

45. Zoghbi J, Xu Y, Grabert R, Theobald V, Richards S. A breakthrough novel method to resolve the drug and target interference problem in immunogenicity assays. J Immunol Methods. (2015) 426:62-9. doi: 10.1016/j.jim.2015.08.002

46. Schmidt E, Hennig K, Mengede C, Zillikens D, Kromminga A. Immunogenicity of rituximab in patients with severe pemphigus. Clin Immunol. (2009) 132:334-41. doi: 10.1016/j.clim.2009.05.007

47. Hernandez-Breijo B, Chaparro M, Cano-Martinez D, Guerra I, Iborra M, Cabriada JL, et al. Standardization of the homogeneous mobility shift assay protocol for evaluation of anti-infliximab antibodies. Application of the method to Crohn's disease patients treated with infliximab. Biochem Pharmacol. (2016) 122:33-41. doi: 10.1016/j.bcp.2016.09.019
48. Robinson JE, Hastie KM, Cross RW, Yenni RE, Elliott DH, Rouelle JA, et al. Most neutralizing human monoclonal antibodies target novel epitopes requiring both Lassa virus glycoprotein subunits. Nat Commun. (2016) 7:11544. doi: 10.1038/ncomms11544

49. Hayakawa K, Hardy RR, Herzenberg LA. Peritoneal Ly-1 B cells: genetic control, autoantibody production, increased lambda light chain expression. Eur J Immunol. (1986) 16:450-6. doi: 10.1002/eji.1830160423

50. Rowley B, Tang L, Shinton S, Hayakawa K, Hardy RR. Autoreactive B-1 B cells: constraints on natural autoantibody B cell antigen receptors. J Autoimmun. (2007) 29:236-45. doi: 10.1016/j.jaut.2007. 07.020

51. Pasparakis M, Alexopoulou L, Episkopou V, Kollias G. Immune and inflammatory responses in TNF alpha-deficient mice: a critical requirement for TNF alpha in the formation of primary B cell follicles, follicular dendritic cell networks and germinal centers, and in the maturation of the humoral immune response. J Exp Med. (1996) 184:1397-411. doi: 10.1084/jem.184.4.1397

52. Kantor AB, Herzenberg LA. Origin of murine B cell lineages. Annu Rev Immunol. (1993) 11:501-38. doi: 10.1146/annurev.iy.11.040193.002441

53. Bar-Yoseph H, Pressman S, Blatt A, Vainberg SG, Maimon N, Starosvetsky E, et al. Infliximab-tumor necrosis factor complexes elicit formation of anti-drug antibodies. Gastroenterology. (2019). doi: 10.1053/j.gastro.2019.08.009

54. Vaisman-Mentesh V, Rosenstein S, Yavzori M, Dror Y, Fudim E, Ungar B, et al. Molecular landscape of anti-drug antibodies reveals the mechanism of the immune response following treatment with TNF $\alpha$ antagonists. biorxiv. (2019). doi: $10.1101 / 509489$

Conflict of Interest: The authors declare that the research was conducted in the absence of any commercial or financial relationships that could be construed as a potential conflict of interest.

Copyright () 2019 Vaisman-Mentesh, Rosenstein, Yavzori, Dror, Fudim, Ungar, Kopylov, Picard, Kigel, Ben-Horin, Benhar and Wine. This is an open-access article distributed under the terms of the Creative Commons Attribution License (CC BY). The use, distribution or reproduction in other forums is permitted, provided the original author(s) and the copyright owner(s) are credited and that the original publication in this journal is cited, in accordance with accepted academic practice. No use, distribution or reproduction is permitted which does not comply with these terms. 